أقسهم هحمب رشكيى المهتيه

أثر جودة الحياة الوظيفية في تنمية سلوك المواطنة التظظيمي

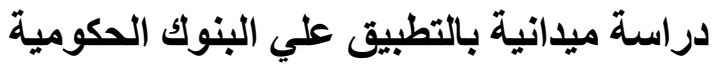

أدهم محمد رشدي الفقي بلئي

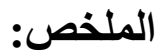

هدفت الدراسة للتعرف علي جودة الحياة الوظيفية وتأثثر ها علي تنمية سلوكيات

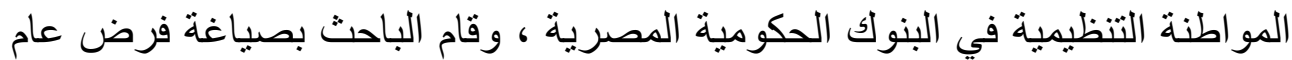

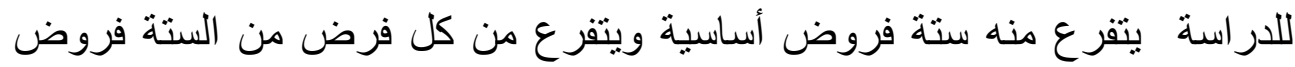

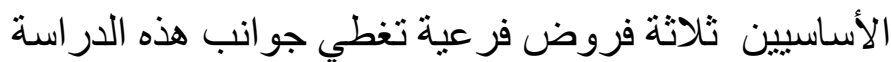

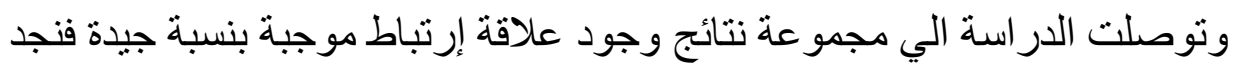

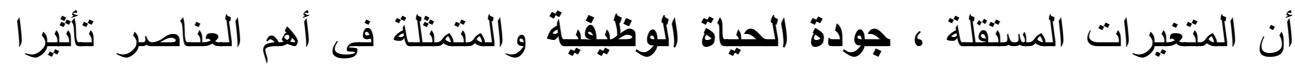
(جماعة العمل - ظروف بيئة العمل - خصائص الوظيفة ـ المشاركة في اتخاذ القرارات) ذات تأثير معنوي على سلوك اعلى المواطنة التظيمي.

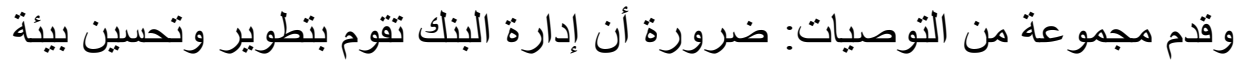

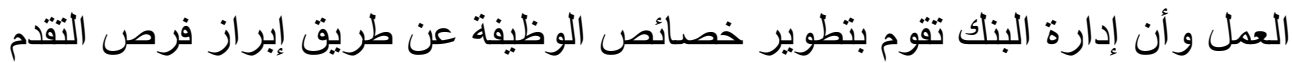

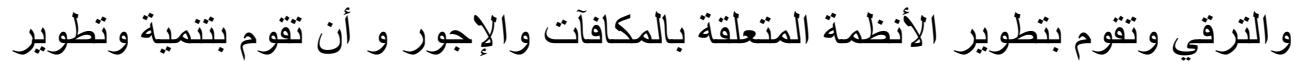

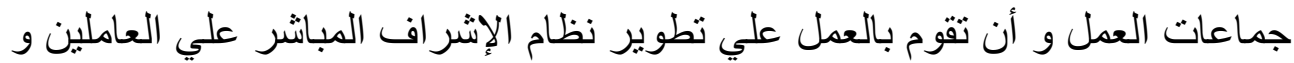

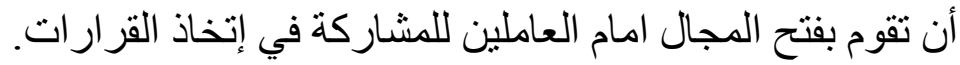

\title{
Abstract:
}

\section{Research Objectives:}

1 - Understand the concept of quality of life, functional and its various dimensions.

2 - Determine the relative importance of each of the quality of working life dimensions and how it relates to each dimensions of citizenship behaviors?

3- know Extent of realizing the management banks under consideration of the importance of the application of the quality 


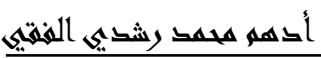

of working life program?

The results of the study are the existence of a significant effect of statistical significance for the impact of the dimensions of the quality of working life on development dimensions of citizenship behaviors. Main six hypothesis: The most important recommendations: The need to consolidate and deploy organizational values positive among all staff the Banks through the handle and interact conscious fruitful with the technical data of scientific knowledge for innovation and excellence in performance, with work on the search for ways to take advantage of the knowledge management exchanged and transferred between parts of the Banks in order to move the Bank into an institution of knowledge. government banks needs concern citizenship behaviors.

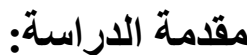

ظهر مفهوم جودة حياة العمل ليواكب سياسات التغيير والتطوير التنظيمي

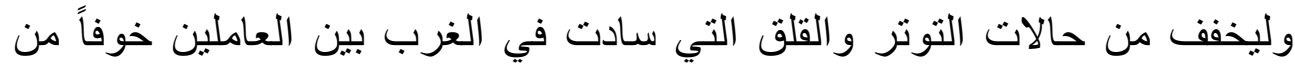

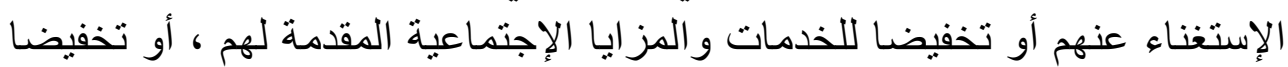

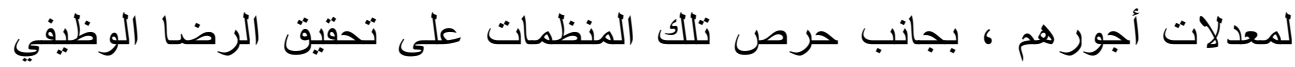

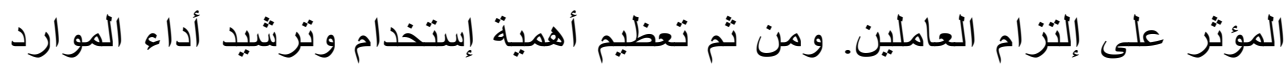

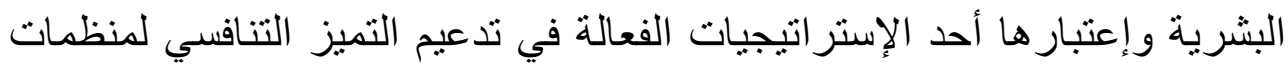

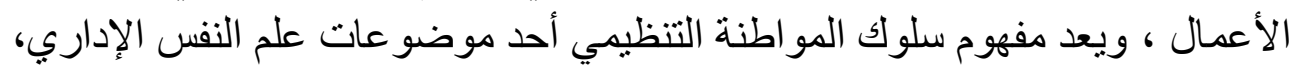

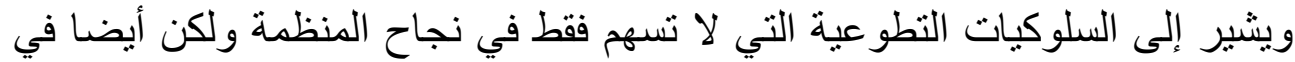

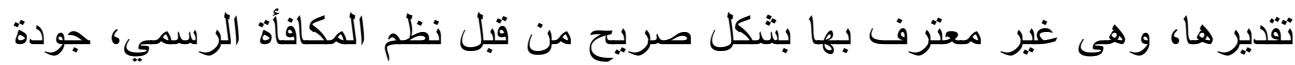

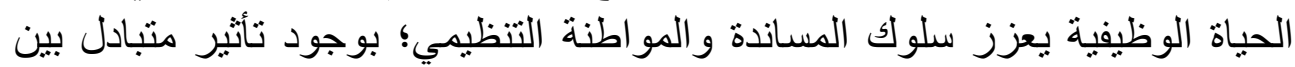

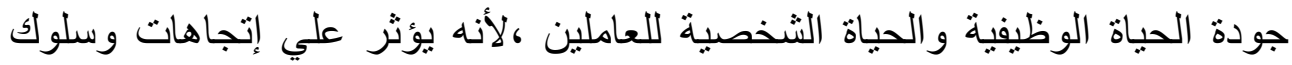

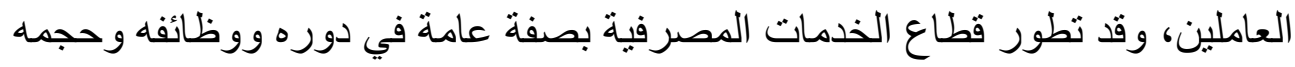




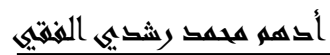

و إمكانياته وتقنياته و هياكله وتتظيماته، فأصبحت البنوك الحكومية تمنلك منل معظم المنظمات الحديثة إدارة خاصة للموارد البشرية تقوم بمهام رئيسية منها إستقطاب العاملين بما يتلائم مع إحتياجاتها و القيام بالتدريب و التأهيل وتحليل الوظائف وتحديد الإجور وتحفيز هم ووضع برامج لجودة الحياة الوظيفية للعاملين بها لرفع كفاءة الأداء وزيادة الإنتاجية وبالتالي إنعكاسه علي البنك الحكومي ، فكان لابد من وجود برامج برد لجودة الحياة الوظيفية للعاملين بها وذلك لأهمية هذا الجهاز الضخم. أولا: الدر اسساث السابقة: ادراسة (0 . . ب) زكي والمقدمة بعنوان : " دور النقابات العمالية في تحسبن جودة الحياة الوظيفية للعاملين - دراسة ميدانية: هدفت أ)التعرف علي الطرق و الأساليب التي يمكن للنقابات إتباعها لتحسين الحياة الوظيفية للعاملين داخل المنظمات وخارجها والتي تؤثر علي إنتاجية هذه المنظمات. ب) تحديد الفجوة بين الدور المطلوب من النقابات العمالية و الدور الموجود فعلا من خلال من خلال التعرف علي الفروق الموجودة بين الثركات التي توجد بها لجان نقابية والتي لا يوجد بها لجان نقابية فيما يتعلق بجودة الحياة الوظيفية. وإستتجت أ) جودة الحياة الوظيفية مفهوم و اسع يتكون من مجموعة من الأركان الأساسية التي يجب أن تتو افر حتي ينجح هذا المفهوم.ب) أن نجاح مفهوم جودة الحياة الوظيفية إنما يتوقف علي وجود علاقة قوية بين كل من أصحاب الثركات ، أعضاء الإدارة العليا ، بيئة العمل، والعاملين و أعضاء النقابات العمالية. ج) أن مشاركة العاملين في إتخاذ القرارات ، المكافآت وتحديد المعدلات الوظيفية بساهم في تحسين الإنتاجية. ץ.دراسة Indumathi\& selvan (2014) والمقدمة بعنوان: "جودة الحياة الوظيفية و التقييم الذاتي للعو امل و الكميات الثابتة للأداء"وهدفت أـالتعرف علي دور جودة الحياة الوظيفية في تحسين الأداء التنظيمي وتحقيق رضا العاملين.ب-شملث

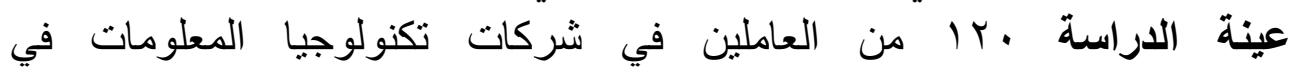
تشيناي.وإستتبت أـأهم العوامل التي تسهم في تحقيق جودة حياة العمل هو تحقيق التوازن بين العمل والحياة ، و التعويض الكافي ، و التكامل الاجتماعي، و الأمان الوظيفي ، وسياسات الإدارة . ب. دراسة Nur (2015 والمقدمة بعنوان :"تقيميم جودة الحياة الوظيفية بين العمال الماليزيين " وهدفت أـ هدفت الدر اسة الي تحديد مدي جودة الحياة الوظيفية في 


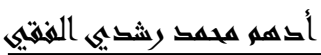

مجال الصحة المهنية ـ وإستتتبت أ_خلصت النتائج إلي ان جودة الحياة الوظيفية قد تختلف من مدينة لأخري ومن بلد لأخر بسبب التفاوت بين درجة التأثثر في ثقافات

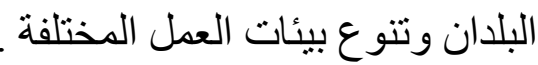

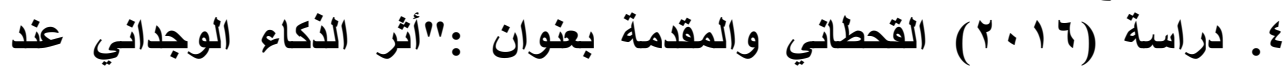

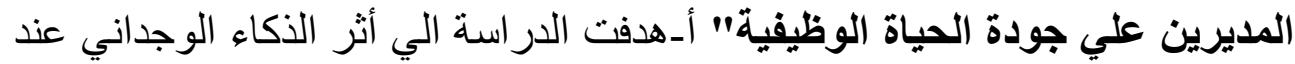

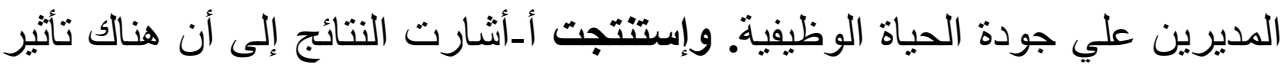

كبير مباشر وموجب بين الذكاء الوجداني عند المديرين علي جودة الحياة الوظيفية. ه. دراسة Kasemsap, Kijpokin (2012) والمقدمة بعنوان:" نموذج للعو امل السبية المؤثرة على سلوك المواطنة التنظيمية لدى شركات تصنيع سيارات نقل واتل الركاب في تايلاند .". وهدفت أـهدفت إلى وضع إطار لمفهوم سلوك المواطنة

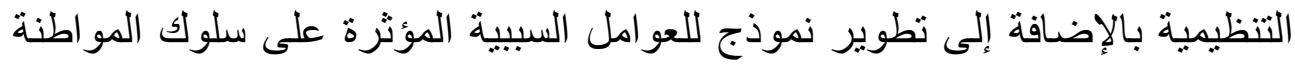

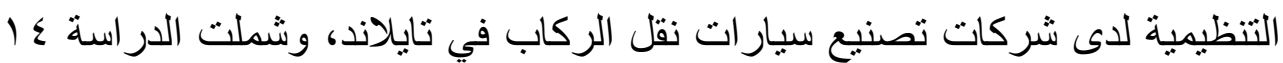

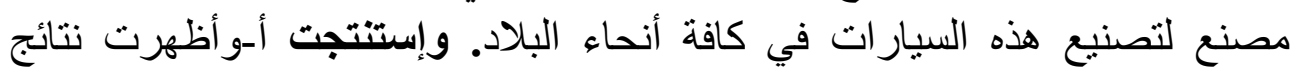

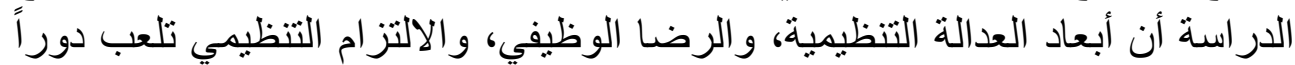

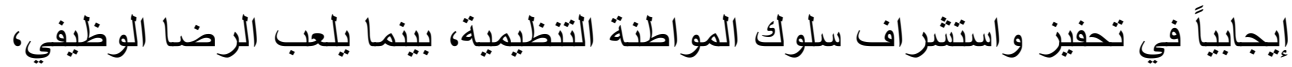
والالتزام الوظيفي دوراً وسيطاً للعلاقة بين العدالة التنظيمية وسلوك التهن المواطنة

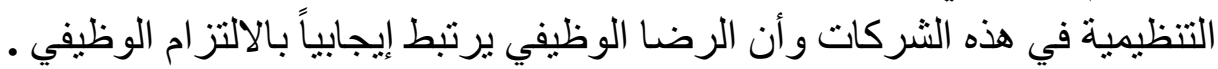
7. دراسة (Osama,2016) والمقدمة بعنوان" العلاقة بين سلوك فئو المواطنة

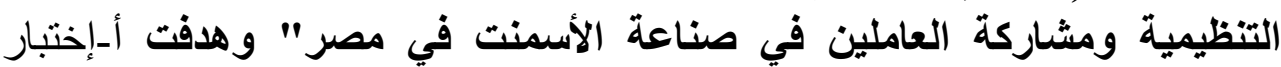

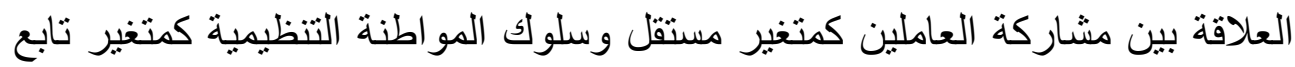
بـإستهدفت دراسة العلاقة بين مشاركة العاملين وسلوك المواطنة التظظيمية في

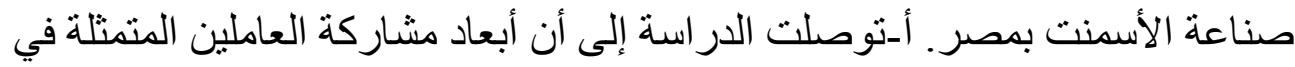

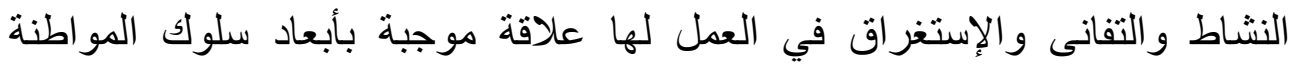
التنظيمية.ب_أظهرت أن هناك علاقة موجبة مباشرة ذات دلالة فئة معنوية بين مشاركة

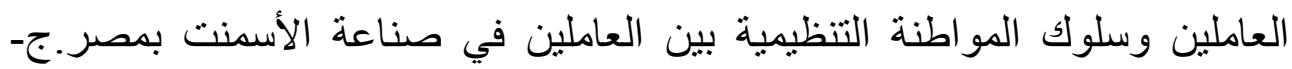

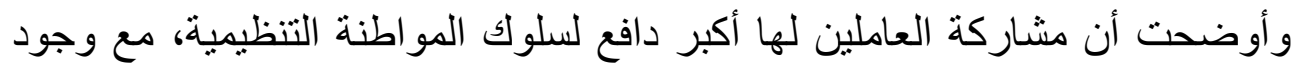
علاقة مرتفعة ذات دلالة معنوية بين المتنغيرين. 


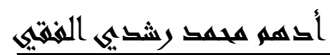

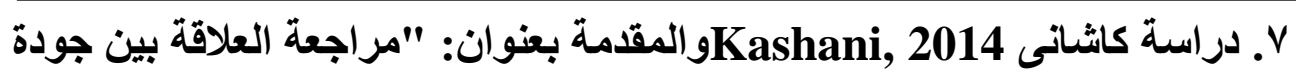

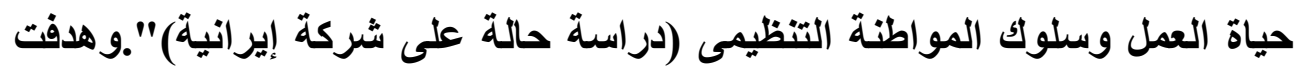

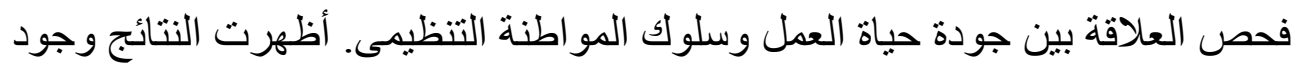

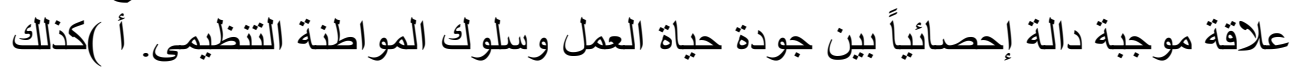

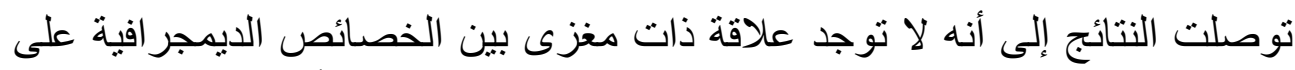

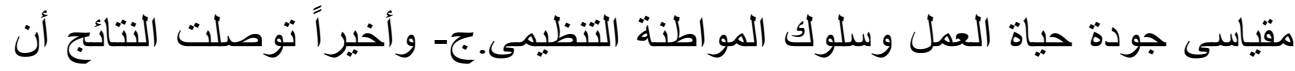

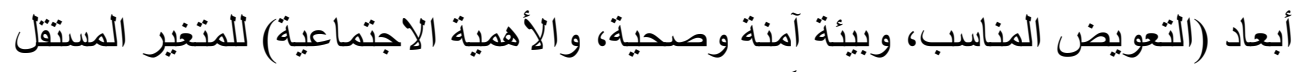

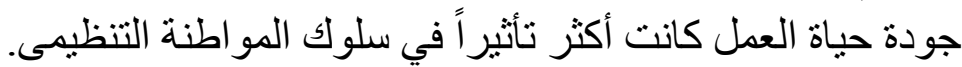
ثانيا: الاراسة الإستطلاعية:

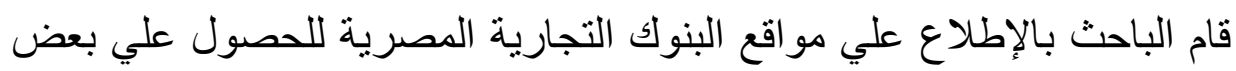

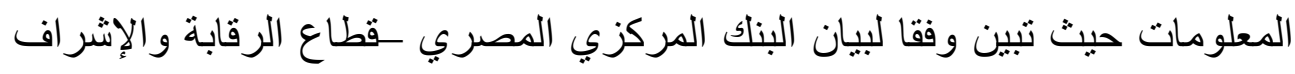

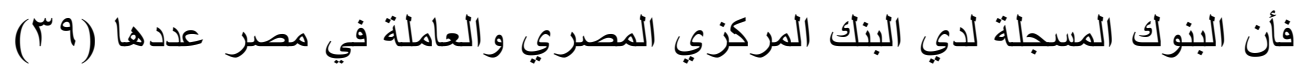
بنكان

وقام الباحث بعمل مقارنة بين البنوك الحكومية المصرية و عدد من البنوك الخاصة

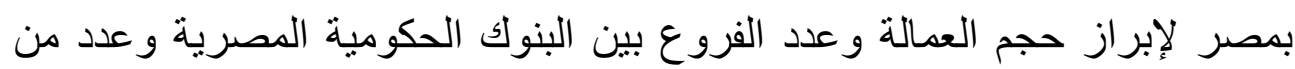

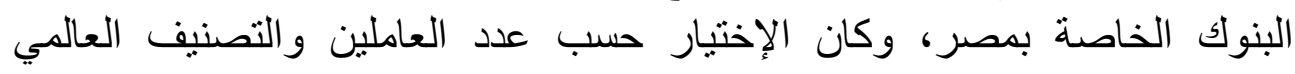
و الإفريقي و الملكية. وقد إستهدفت الدراسة الإسنطلاعية تحديدة بلورة مشكلة الدراسة وذللك بتحديد مدى تمتع العاملين بقطاع البنوك بجودة الحياة الوظيفية وعلاقة ما يتمتع بـه العاملون

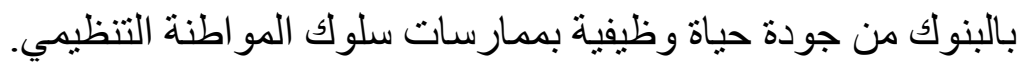

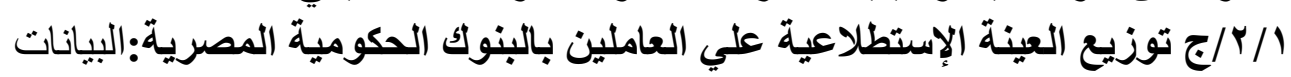
الميدانية : الإستقصاء: توزيع العينة الإعاء قام الباحث بإعداد قائمة إستقصاء مبدئية تتضمن توجيه أسئلة تتعلق بجودة الحياة

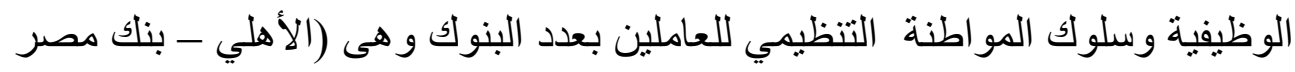

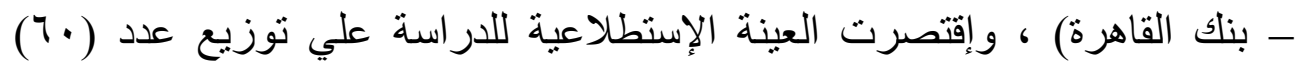

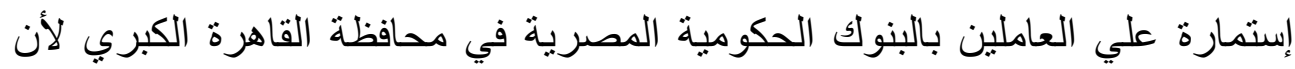

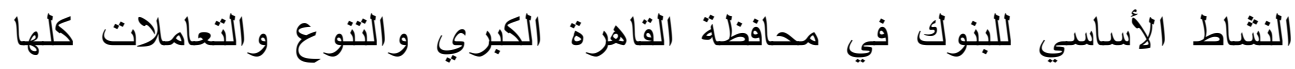
بالخدمات يقدم من خلال هذه المحافظة وقد تم تحديد نسب توزيع إستمارات 


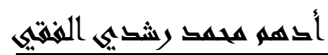

الإستقصاء علي البنوك الثلاثة طبقا لنسب إجمالي عدد العاملين بكل بنك من البنوك

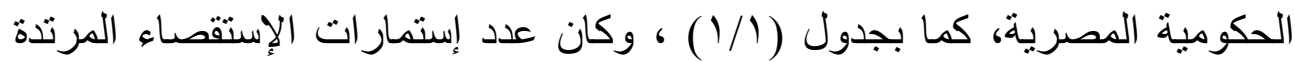

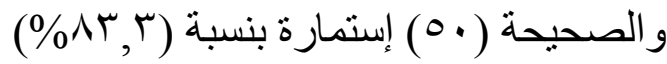

\section{تحليل نتائج الدراسة الإستطلاعية:}

() إنخفاض بعض أبعاد جودة الحياة الوظيفية لدى العاملين مثل بعد الأمان

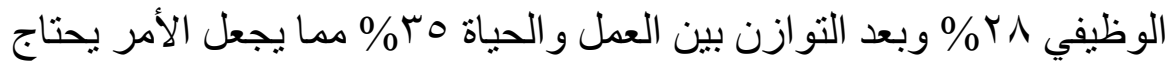

$$
\text { إلى مزيد من الدراسة. }
$$

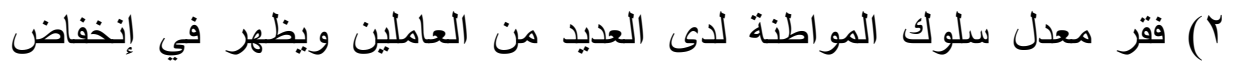

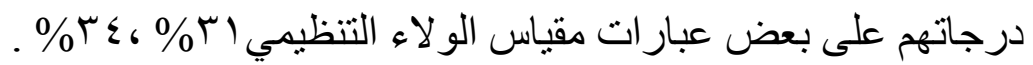

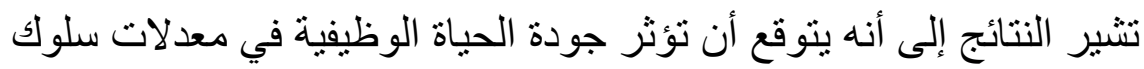
المواطنة التنظيمي الصادر من العامل وبالتالي نحن في حاجة إلى إلى فهم الآلية التي يؤثر بها جودة الحياة الوظيفية في سلوك المو اطنة التهي التظيمي.

ثالثا : مشكلة الدراسة:

وقد تم عرض مشكلة الدر اسة في تساؤلات والتي سوف تحاول الدر اسة الإجابة عنها

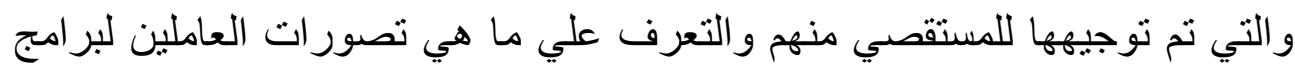
جودة الحياة الوظيفية وعلاقتها بسلوك المواطنة التنظيمي ويمكن صياغة مشكلة

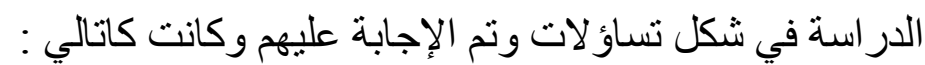

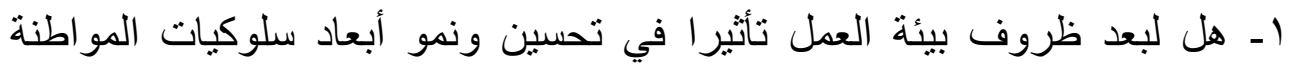

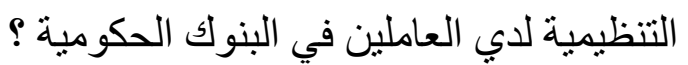
r- هل بعد خصائص الوظيفة دورا في تحسين ونمو أبعاد سلوكيات المواطنة

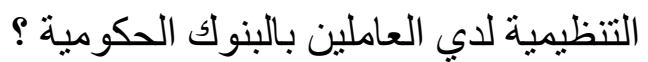

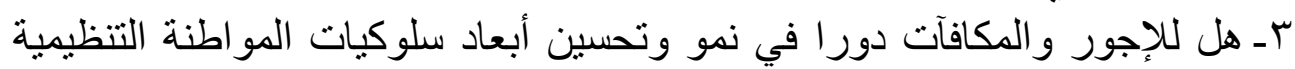

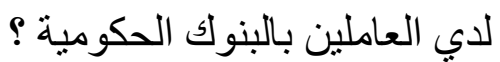
ع ـ هل لجماعة العمل دورا في تحسين أبعاد سلوكيات المو اطنة التتظيمية لدي العاملين

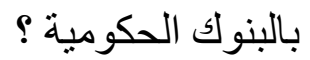
هـ هل لإسلوب الرئيس في الإشراف دورا في تتمية أبعاد سلوكيات المواطنة 


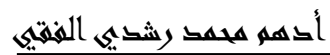

التنظيمية لدي العاملين بالبنوك الحكومية ؟

7ـ هل لبعد المشاركة في إتخاذ القرارات دورا في نمو أبعاد سلوكيات المواطنة

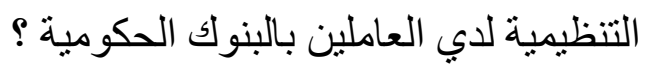

Vـ هل لجودة الحياة الوظيفية دورا في تحسين ونمو سلوكيات المواطنة التنظيمي لدي لئي

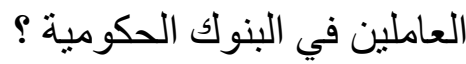

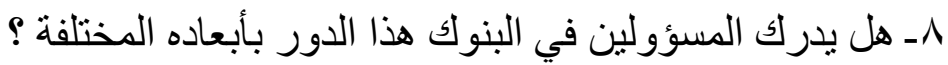

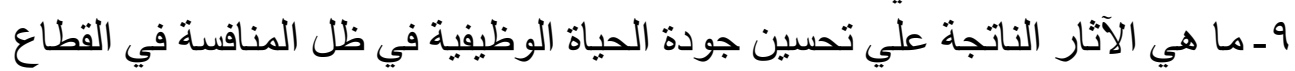

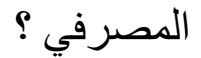
• ا ـ ما هي المزايا التي يمكن أن تحققها البنوك في حالة تبنيها تطبيق بر امج جودة

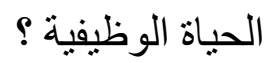

\section{رابعا: أهمية الاراسة: \\ الأهمية العلمية : الأسة:}

1 ـ الدراسة تأتي دعما لغير ها من الدراسات السابقة ويضيف اليها در اسة

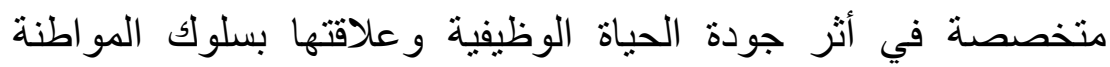

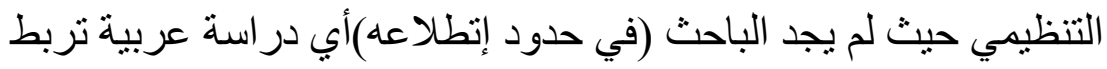

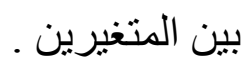

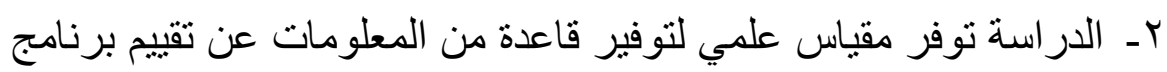

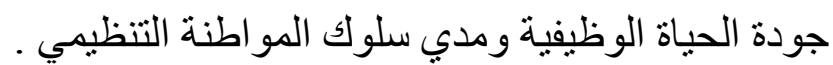

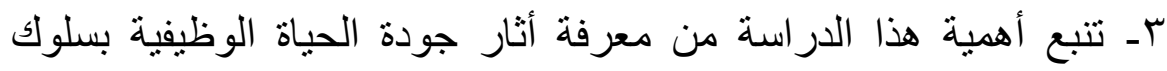

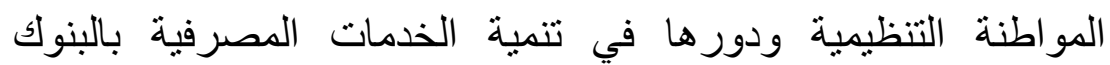

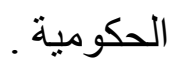

بـ الأهمية التطبيقية : التكومية

ا ـ الأهمية الكبري للبنوك الحكومية نظر الحيفة لحصتها الكبيرة بالنسبة للقطاع

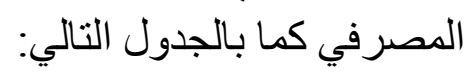




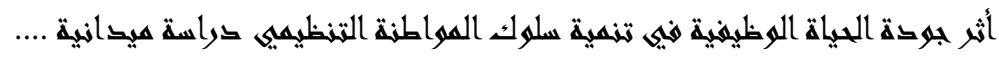

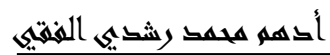

\section{جدول(1) (1)}

نسبة الحصة السوقية للبنوك الحكومية

\begin{tabular}{|c|c|c|c|c|c|}
\hline باقي الخاصة البنوك & البنوكالإمية & بنك القاهرة & بنلك مصر & البنك الأهلي & البيان \\
\hline$\% \leqslant q, V$ & $\% 0$ & $\% \leqslant, 0$ & $\%$ & $\% \Gamma$. & السبة \\
\hline
\end{tabular}

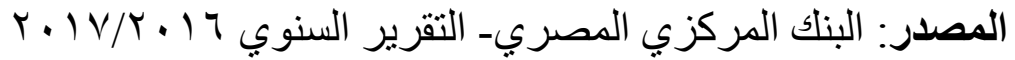

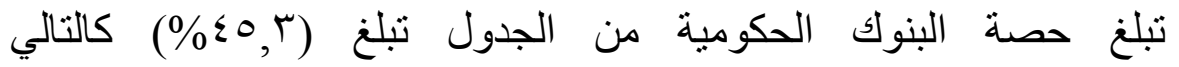

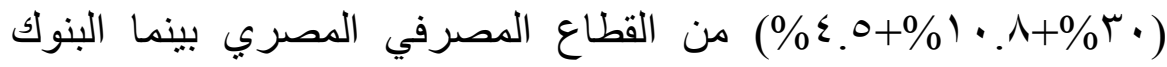

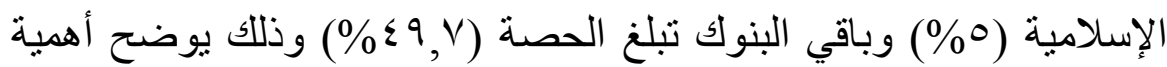

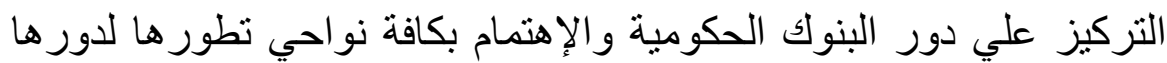

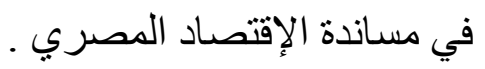
خامسا: أهداف الدراسة:

تهدف الدر اسة لتحقيق العديد من الأهداف العلمية و العملية ونوجز ها كالتالي: اـ التعرف علي جودة الحياة الوظيفية: من حيث المفهوم وأهداف تطبيقها

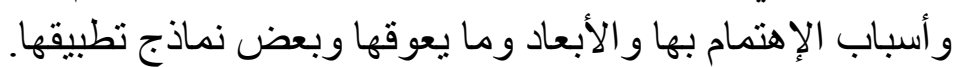
Yـ التعرف علي سلوك المواطنة التنظيمية من حيث المفهوم و العوامل المؤثرة

$$
\text { في تتميته وكيفيه قياسه. }
$$

r- تحديد الأهية النسبية لكل من أبعاد جودة الحياة الوظيفية و علاقتها بسلوك

$$
\text { المو اطنة التنظيمي. }
$$

ع ـ الإرتقاء بسلوك المواطنة التنظيمي في البنوك الحكومية لتجويد العلاقة بين العاملين بهاو الإدار ات بهاو وبالتالي زيادة معدلات الأدي في الأداء والإنتاجية.

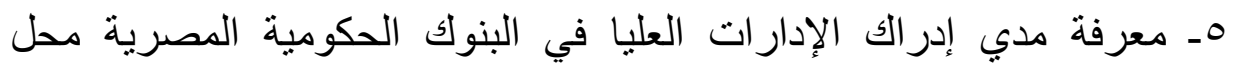

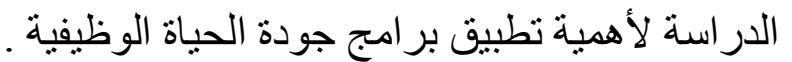

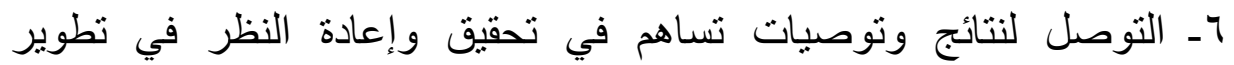
الممارسات الإدارية الخاصة بتطبيق بر امج لجودة الحياة الوظيفية. 
أثر بوقة الحياة الوزيهية هيه تنمية سلوك المواطنة التنظيميه قراسة هيحانية ....

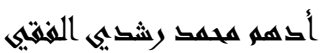

$$
\text { سادسا : فروض الدراسة: الفرض العام للار اسـة: }
$$

يوجد تأثير معنوي ذو دلالة إحصائية لأبعاد جودة الحياة الوظيفية علي

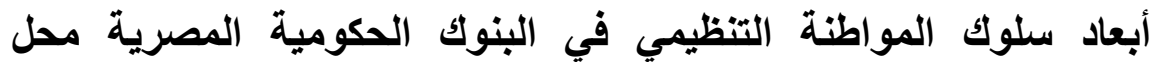

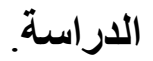

\section{جدول رقم (Y) فروض ومتغير ات الدراسة}

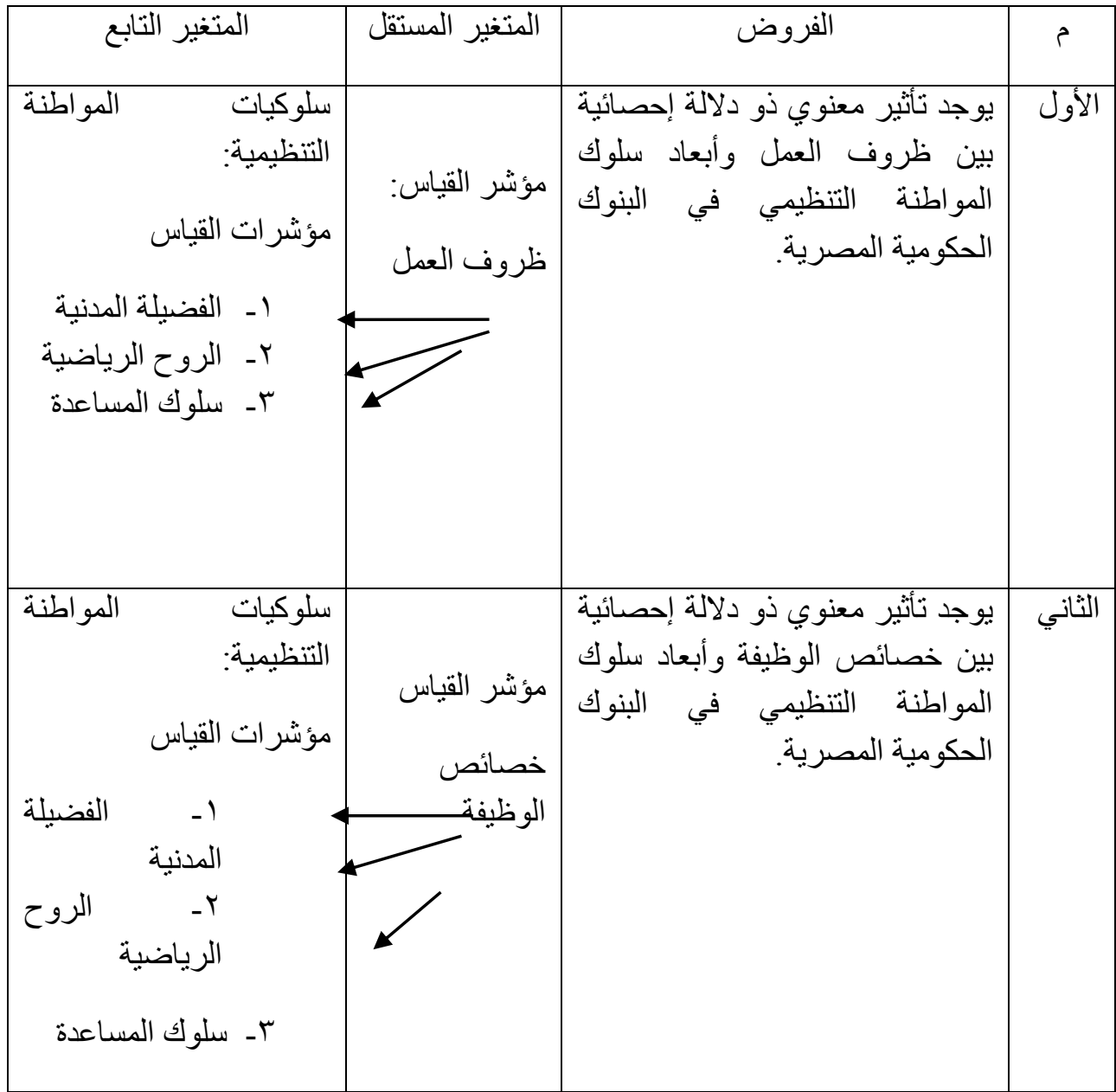




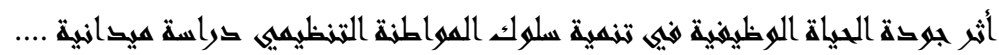

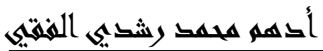

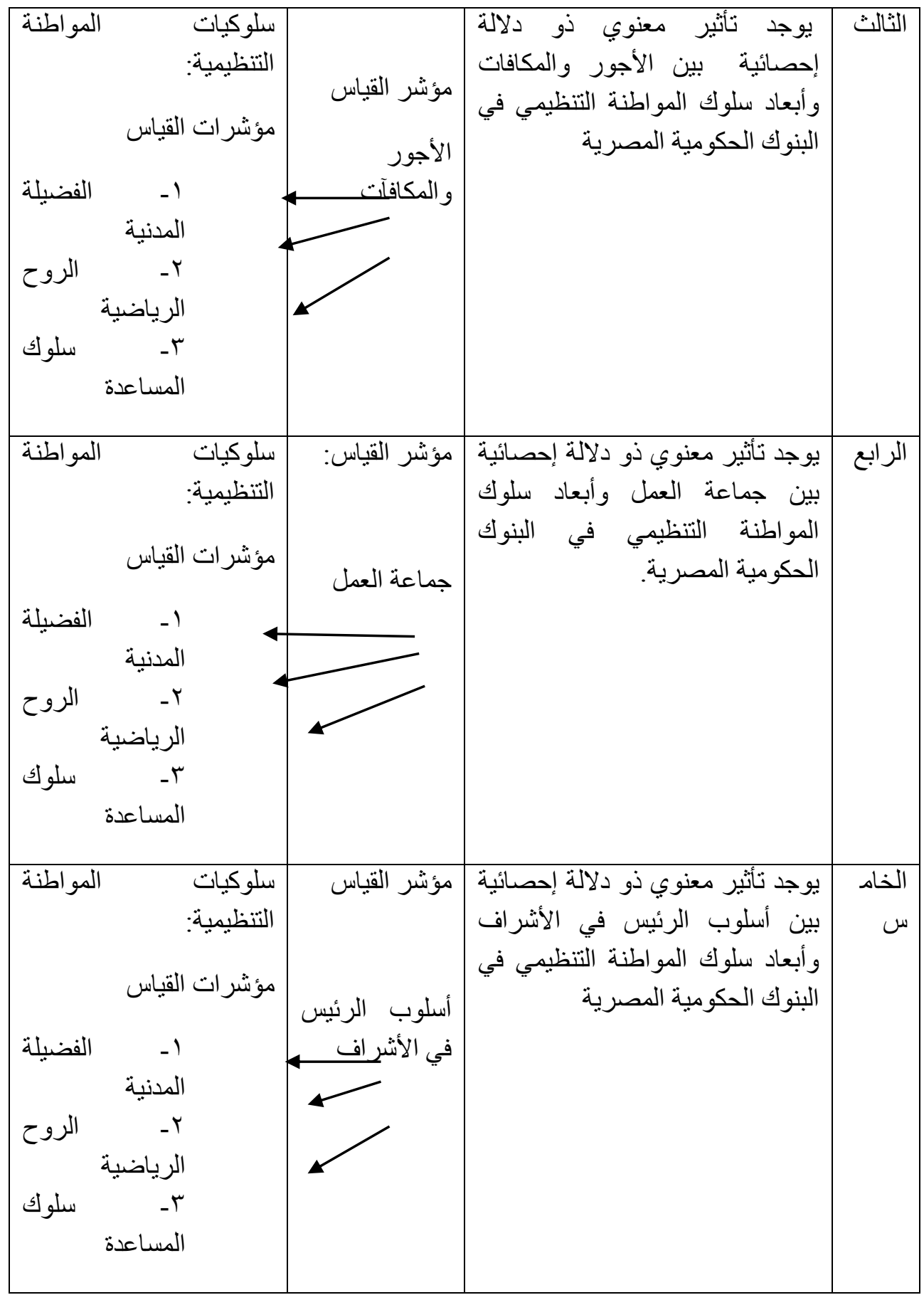

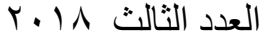




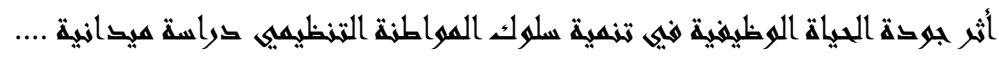

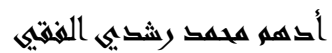

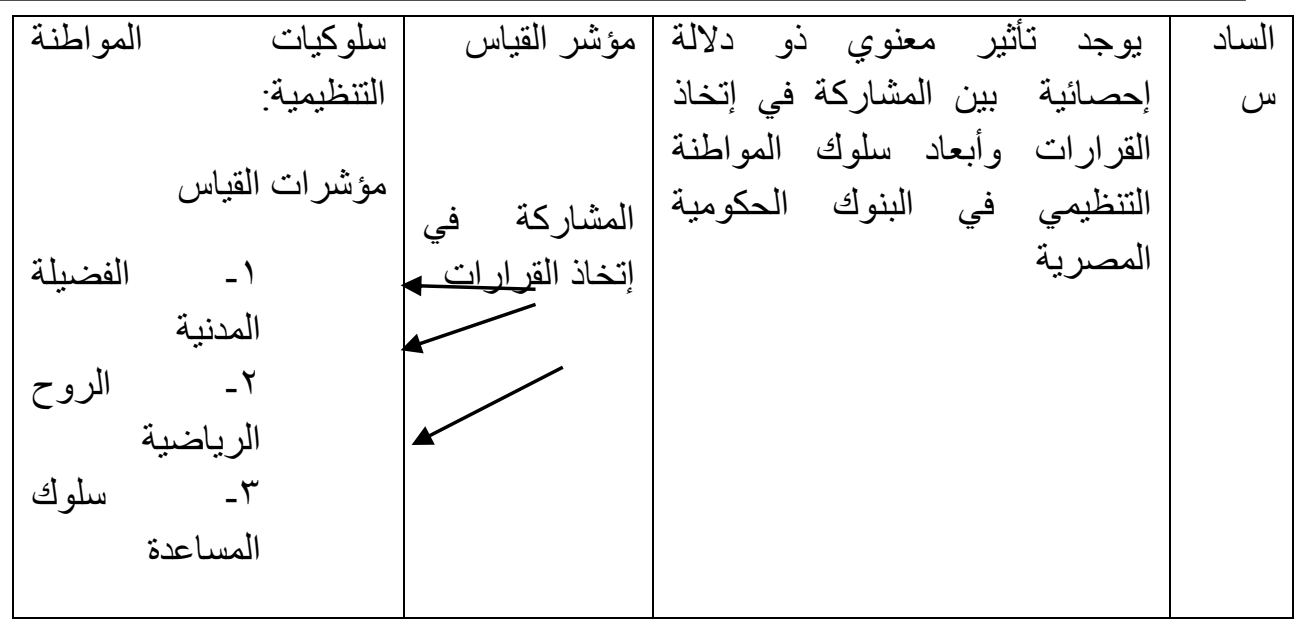

المصدر : من إعداد الباحث إستنادا إلي الدر اسات السابقة.

سابعا: متغير ات الدراسة:

يتضمن هذا الجزء شرحا لمتغير ات الدراسة واستة ويمكن أن نعرفها كما يلي:

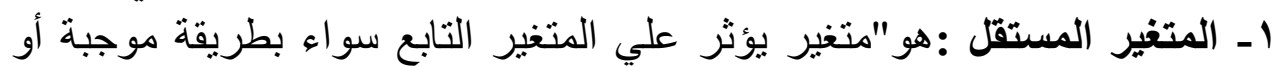

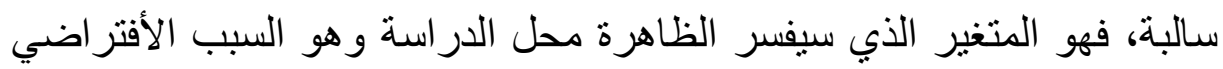

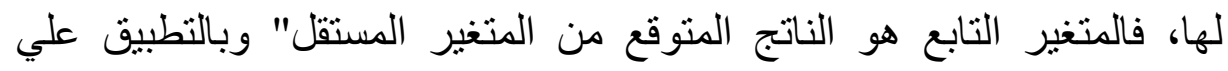

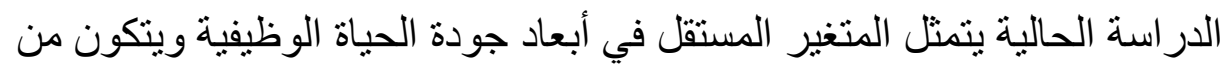

$$
\begin{aligned}
& \text { ستة أبعاد وهم: } \\
& \text { أــ ظروف بيئة العمل. } \\
& \text { ب- خصائص الوظيفة . }
\end{aligned}
$$

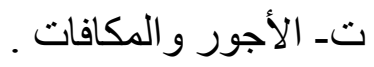

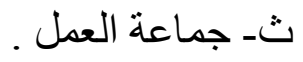

$$
\begin{aligned}
& \text { ج- إسلوب الرئيس في الإشر اف . } \\
& \text { ح- المشاركة في إتخاذ القرار ات التشئ . }
\end{aligned}
$$

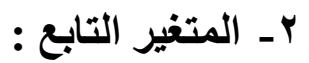

و هو "متغير يكون الإهتمام للباحث فهو هدف الدراسة في شرح وتفسير هذا المتغير

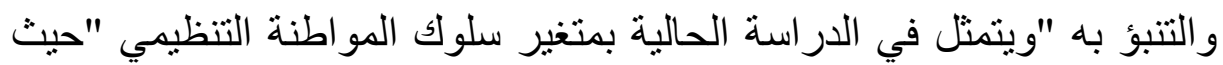

$$
\text { أـ الفضيلة المدنية (السلوك ثلاثة أبعاد وهم: الحضارى). }
$$


أثر بوقة الحياة الموظهية هيه تنمية سلوك المواطنة التنظيميه قراسة هيدانية ....

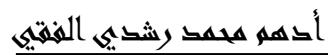

$$
\begin{aligned}
& \text { بـ- الروح الرياضية . }
\end{aligned}
$$

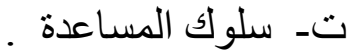

ثامنا: الإطار المفاهيمي لجودة الحياة الوظيفية وسلوك المواطنة التظظيمي:

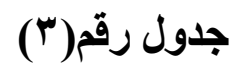

\begin{tabular}{|c|c|}
\hline المفهوم & المؤلف/ الباحث \\
\hline 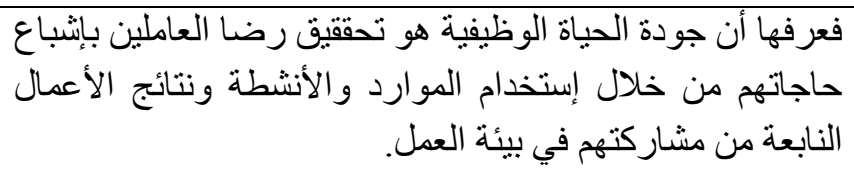 & sirgy,at al (2008) \\
\hline 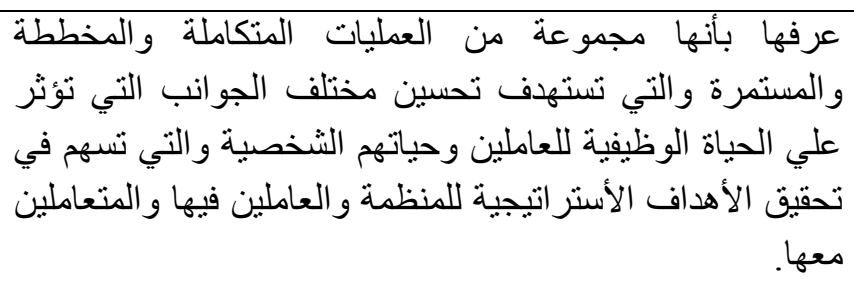 & 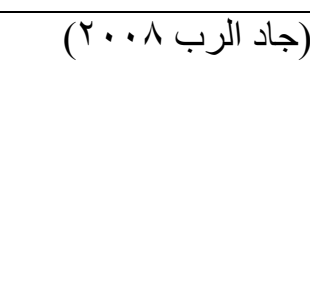 \\
\hline 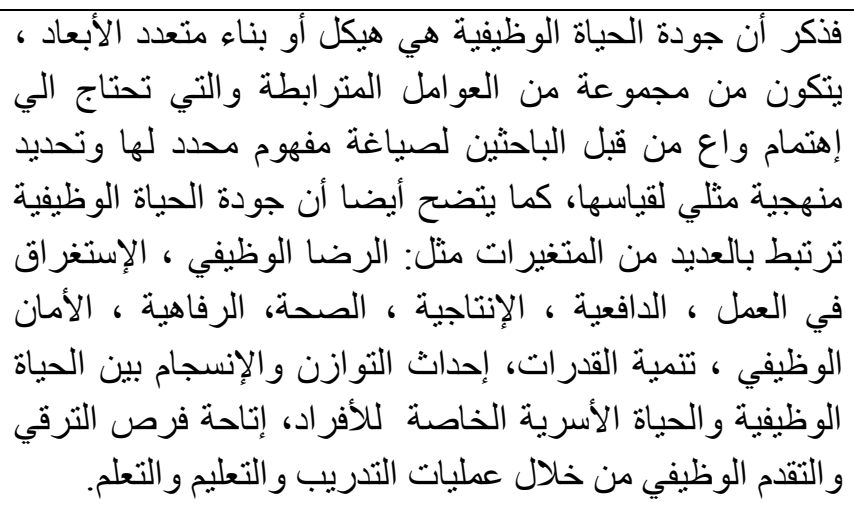 & 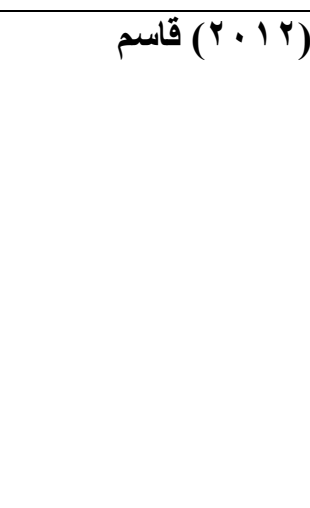 \\
\hline
\end{tabular}

أهم التعريفات التي تناولها الباحثون لجودة الحياة الوظيفية في السابق رئ 


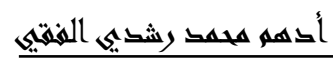

\begin{tabular}{|c|c|}
\hline 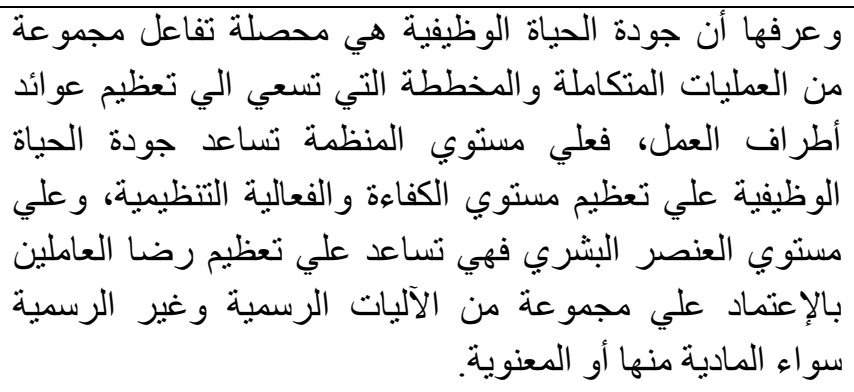 & 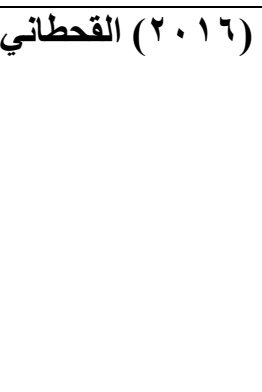 \\
\hline والفرد بالرضها أنه يمكن تعريف جودة الحياة الوظيفية علي أنها : شعور & (Y ( · ) الحنفي \\
\hline
\end{tabular}

$$
\text { المصدر: من إعداد الباحث بالإعتماد علي الدر اسات السابقة. }
$$

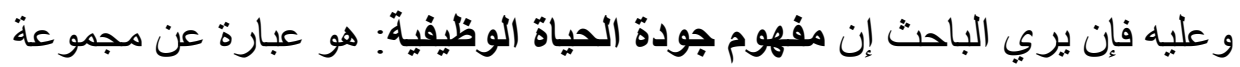

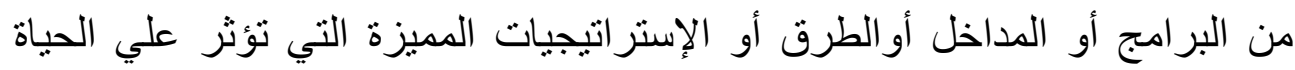

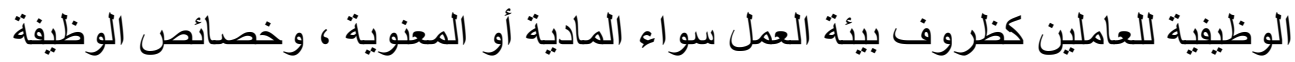

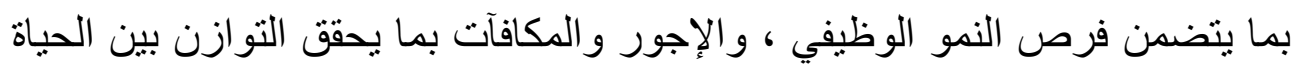

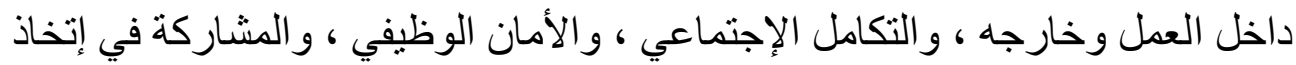

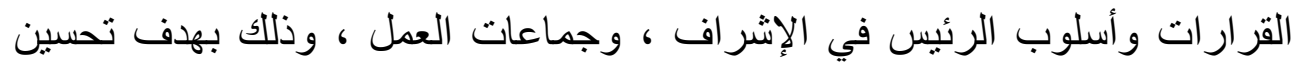

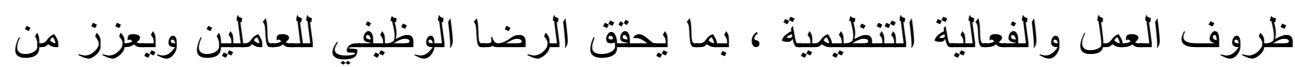

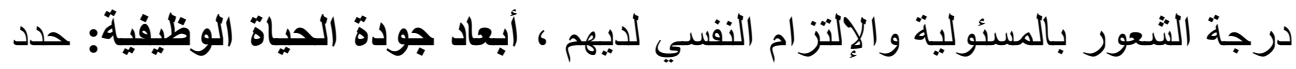

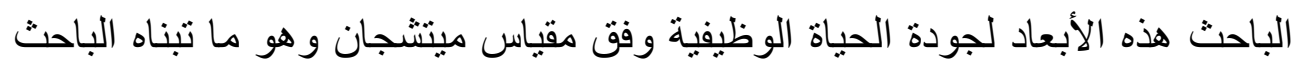
ويعتبره أكثر إستيعابا في قياس جودة الإد الحياة الوظيفية. 
أثثر بوكة الحياة الموظينية هيه تنفية سلوك المواطنة التنظيميى قواسة هيد انية ....

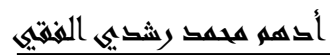

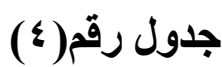

مفاهيم سلوكيات المواطنة التظيمية لبعض المؤلفين والباحثين

\begin{tabular}{|c|c|}
\hline المفهوم & المؤلف/ الباحث \\
\hline 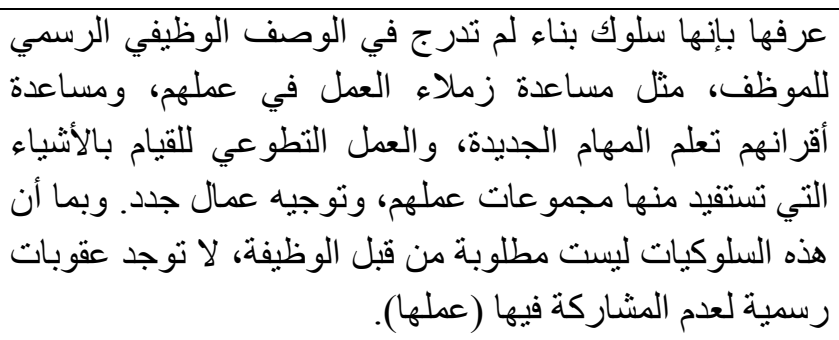 & (Organ\& Bateman1988) \\
\hline 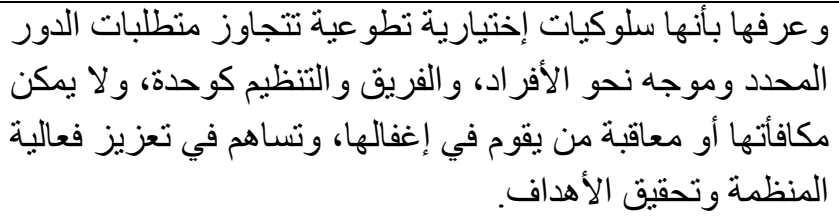 & (Elena,B,Anit.S,2009) \\
\hline 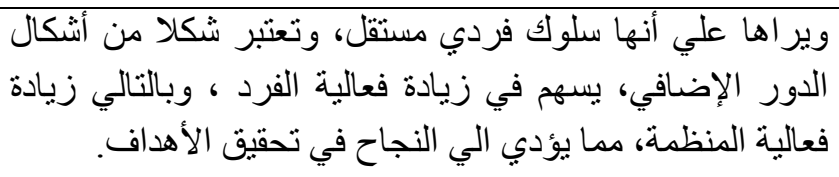 & (Enrico Sevi,2010) \\
\hline 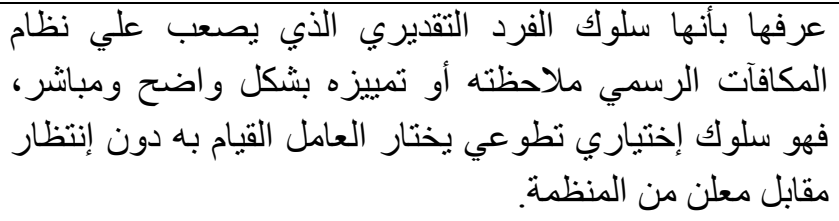 & (Chin, Min-Huei, 2011) \\
\hline 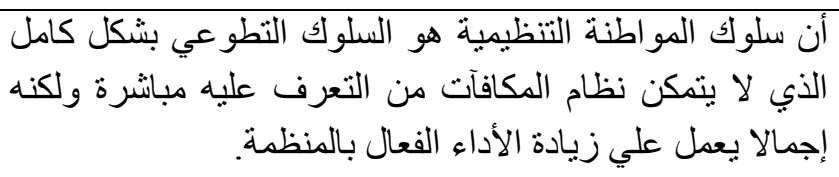 & (Zahra, et al,2013) \\
\hline 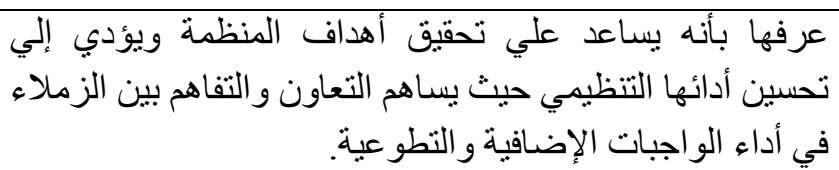 & (Koladeet et al,2014) \\
\hline
\end{tabular}

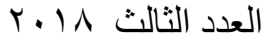




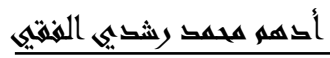

\begin{tabular}{|c|c|}
\hline أو الرسمي وأنها إختبارية منروكيات مرتبطة بالعمل، لا يتضمنها لحكم وتقدير الفرد في ممارستها الوظيفي & (أمام ع I · ( ) \\
\hline تحقيق الأهداف المو اطنة التنظيمية هي إسهامات الأفر اد في إنجاز أو & (Obicci, Peter,2015) \\
\hline 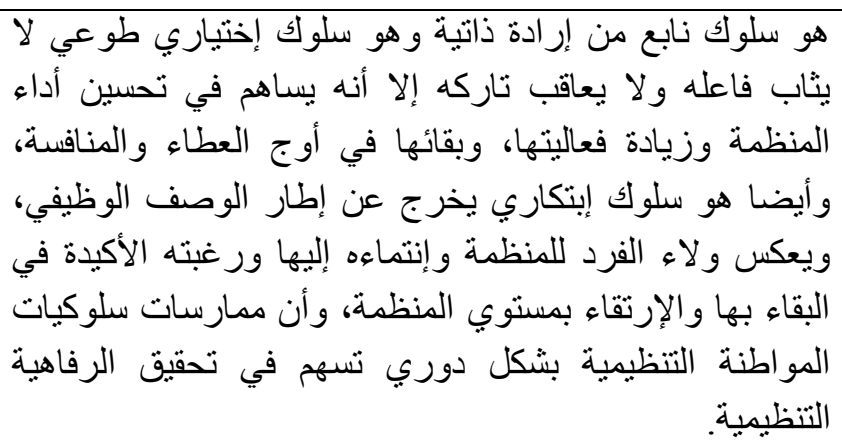 & 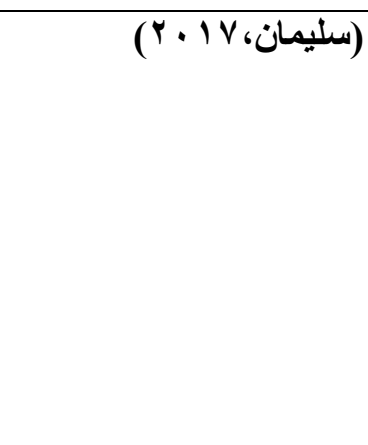 \\
\hline
\end{tabular}

المصدر: من إعداد الباحث بالإعتماد علي الدر اسات السابقة.

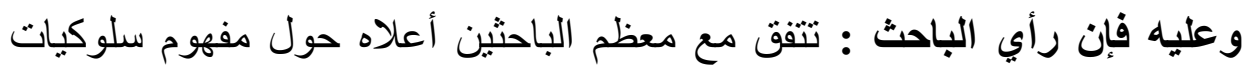

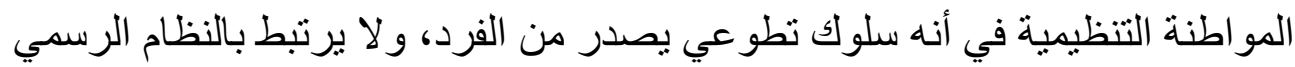

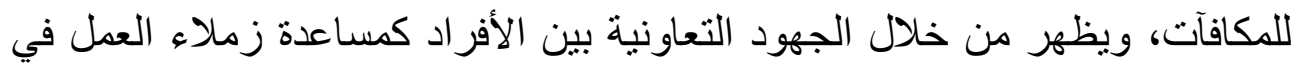

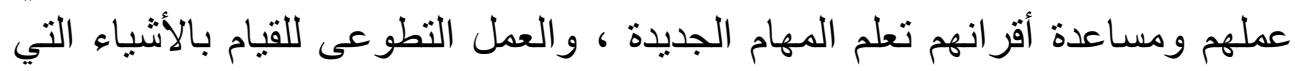

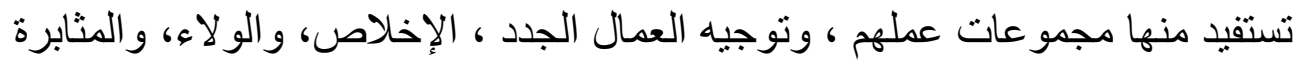

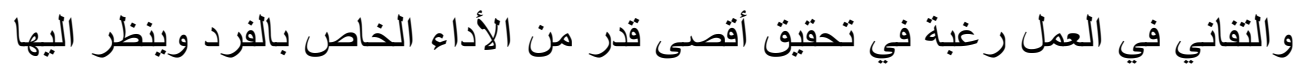
علي أنها مؤشر سلوكى لإستجابات العاملين لعلاقات عملهم.

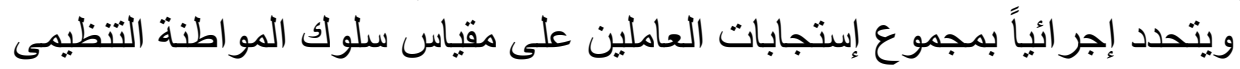

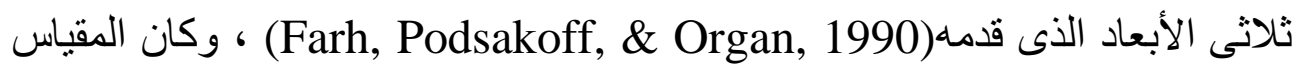
مقياسا ذاتيال OCB عرضت في در اسات لاحقة من (Podsakoff et al., 1997) لقياس OCBG لأعضاء الفريق.

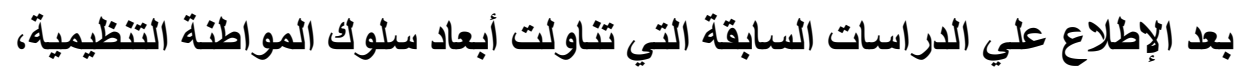

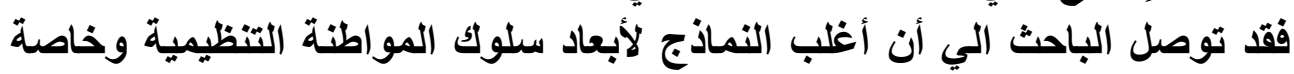

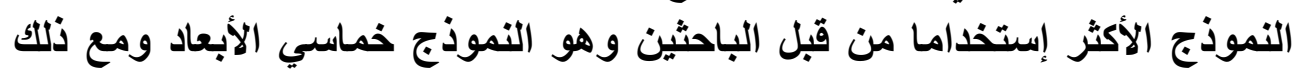




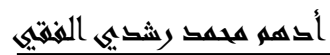

(e.g., MacKenzie, Podsakoff, \& Fetter, البحوث التجريبية المتتالية) 1991, 1993; Podsakoff \& MacKenzie, 1994) المديرين غالبا ما يجدون صعوبة في التعرف علي وأن يميزوا بين هذه الفروق

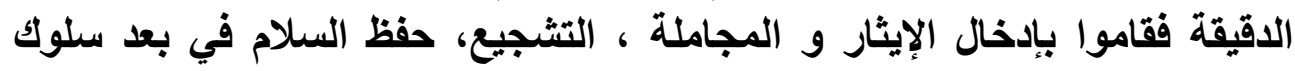

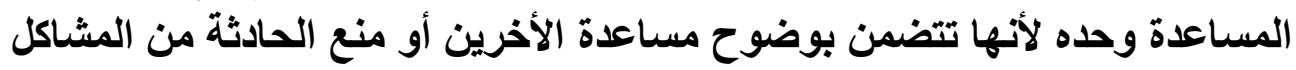

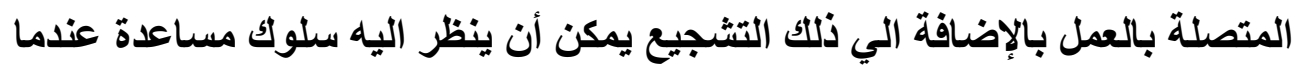
يشجع زميل العمل الأي يشبط إنجاز اتهله

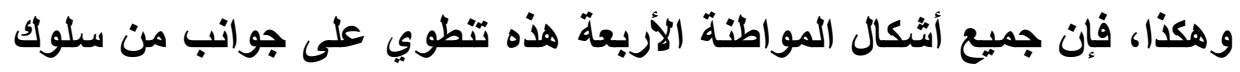

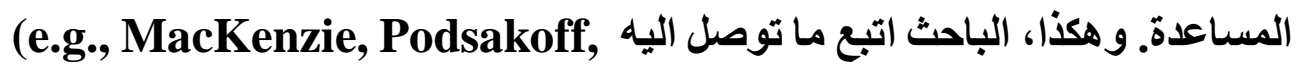
ه Fetter, 1991, 1993; Podsakoff \& MacKenzie, 1994) سلوكيات المواطنة التظيمية، هي الثكل من أشكال سلوك المساعدة ، والروح الرياضة، و الفضيلة المدنية.

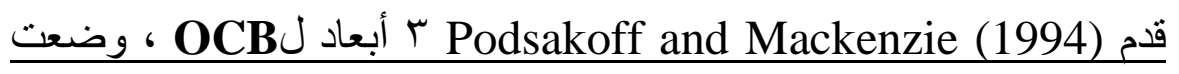

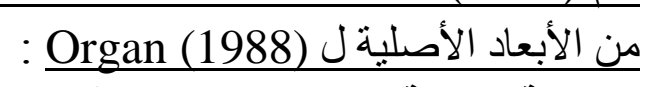

( ) (الفضيلة المدنية Civic virtue (الرقي والتعاون( السلوك الحضاري):

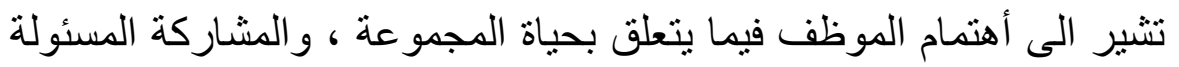

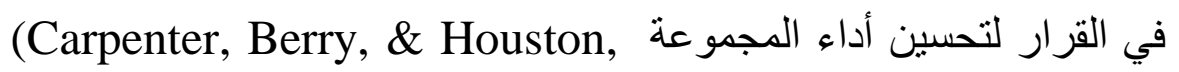
2014; Nielsen et al., 2012).

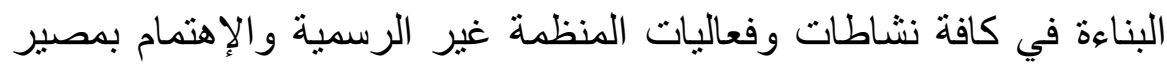

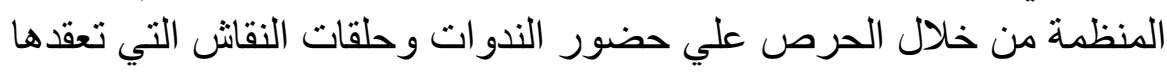

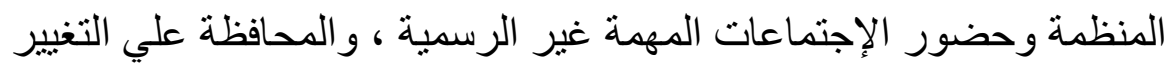

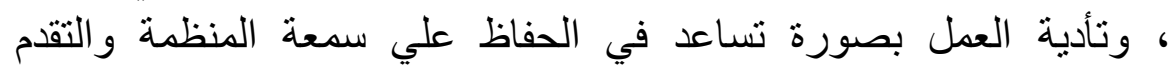

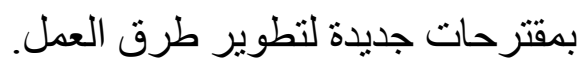

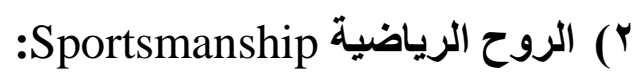
هو مدي إستعداد الفرد لتحمل بعض الإحباطات و المضايقات الثخصية دون النقان

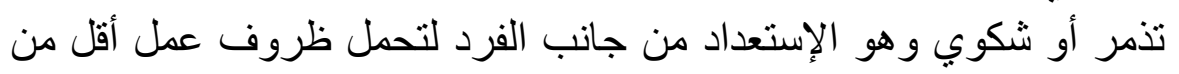

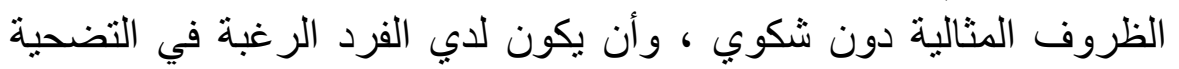
بمصالحه الثخصية من أجل صالح جماعة وان العمل. لئل 


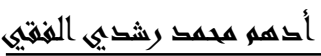

بelping behavior سلوك المساعدة

تعني الإمكانيات النشطة المساعدة لأعضاء آخرين لمجموعة العمل وتجنب المشاكل المتصلة بالعمل ومنعها(Nielsen et al., 2012) و ومساعدة الإنة

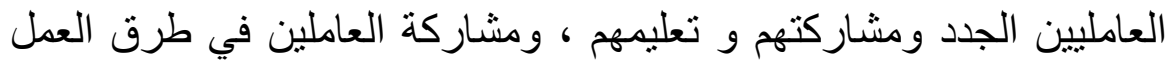

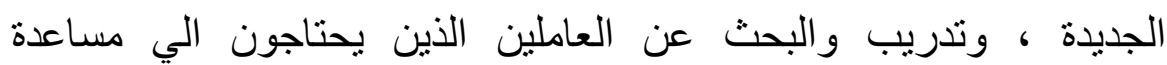

وحمايته.

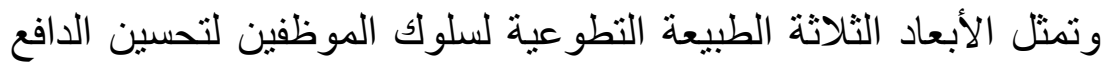
(التحفيز) الإجتماعى والإلنزام والإبداع لفرقهم وبالتالي أداء الفريق

، (George \& Bettenhausen, 1990; Hu \& Liden, 2015). فهناك العديد من الأسباب أن أبعاد سلوك المساعدة والروح الرياضية

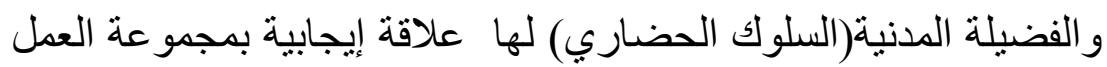
أو الفعالية التنظيمية .

(Borman \& Motowidlo, 1993; George \& Bettenhausen, 1990; Karambayya, 1989; Organ, 1988, 1990; Podsakoff \& MacKenzie,1994,smith, et al 1983).

\section{تاسعا: تحديد مجتمع وعينة الدراسة:

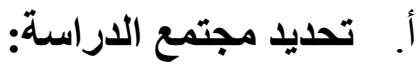

يقتصر مجتمع الدراسة علي العاملين بالبنوك الحكومية المصرية (البنك الأهلي المصري، بنلك مصر ، بنلك القاهرة) حيث بيلغ عدد العاملين

ب ع . . . . موظف في مختلف المستويات الوظيفية. ب. تحديد عينة الدراسة:

قام الباحث بإختيار عينة عشوائية بسيطة وذللك لأن مجتمع البحث غير متجانس حيث تختلف تخصصاتهم ومؤهلاتهم ودرجاتهم العلمية

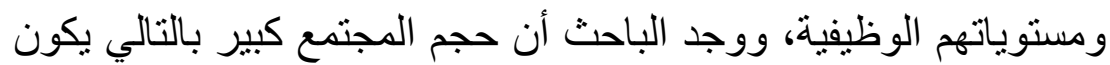

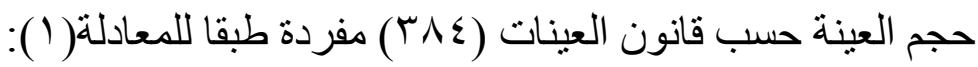

$$
\begin{aligned}
& \mathrm{N}=\frac{t 2 p(1-p)}{d 2} \\
& \text { حيث إن N N N Nم العينة. }
\end{aligned}
$$


أثثر بوكة الحياة الموظينية هيه تنفية سلوك المواطنة التنظيميى قواسة هيد انية ....

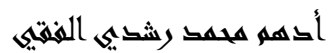

$$
\begin{aligned}
& \text { = T } \\
& \text { = نسبة الإختلاف حيث معامل الثقة } 0 \text { = }
\end{aligned}
$$

= P

$$
\text { أعتبر ها الباحث . 0 }
$$

وبالتعويض في المعادلة ( (1) نجد أن حجم العينة المطلوبة (n)

$$
\begin{aligned}
\mathrm{N}=\frac{(1.96) 2 \times 0.5 \times(0.5)}{(0.05)^{2}}=\frac{3.8416 \times 0.25}{0.0025}=\frac{0.9604}{0.0025} \\
\mathrm{~N}=384
\end{aligned}
$$

\begin{tabular}{|c|c|c|c|c|}
\hline نسبة مجتمع الدراركة البنك من إجمالي & حجم العينة & العمالي & اسم البنك & r \\
\hline$\%$ \% & $1 \leqslant$ & $1 V 17 \leq$ & بنك مصر & 1 \\
\hline$\%$ \% & 149 & $1 V \ldots$ & البنك الأهلي المصري & r \\
\hline 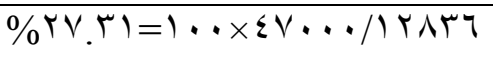 & $1 \cdot 0$ & I rAMt & بنك القاهرة & $r$ \\
\hline$\% 1 \ldots$ & 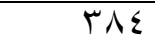 & $\varepsilon \vee \ldots$ & & \\
\hline
\end{tabular}

وقام الباحث بتوزيع حجم العينة المشار البها (ب^ع) مفردة توزيعا

نسبيا بما يتفق مع حجم العمالة في كل بنك محل الدراسة وفقا للجدول

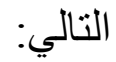

\section{جدول (•) مجتمع وعينة الدراسة}

المصدر: من أعداد الباحث بالإستعانة ببيان البنك المركزي المصري ـالتقرير

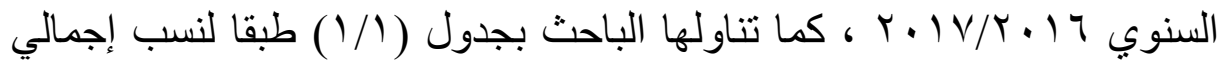
عدد العاملين بكل بنك من البنوك الحكومية المصرية. تم الإعتماد علي عينة عشو ائية بسيطة نظر الأن مجتمع الدر اسة متجانس.

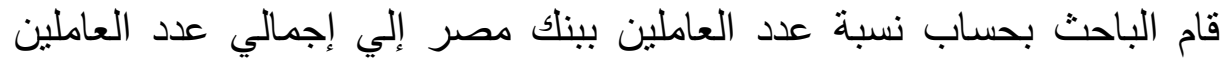

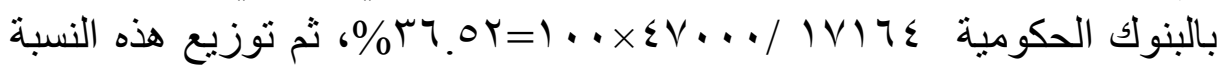
علي إجمالي حجم العينة لمعرفة عدد العينة التي قام الباحث بتوزيعها علي

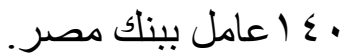




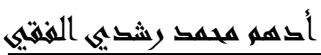

وقام الباحث بحساب نسبة عدد العاملين ببنك القاهرة إلي إجمالي عدد العاملين

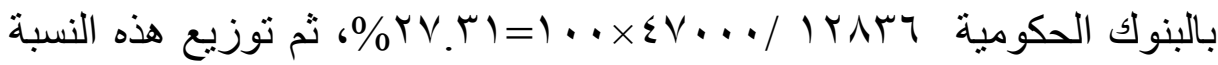

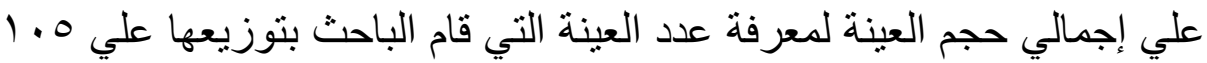

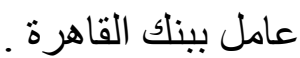

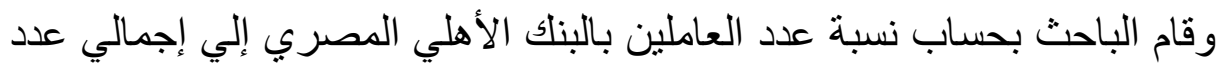

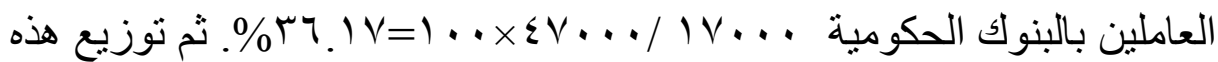

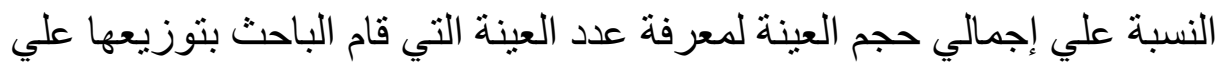

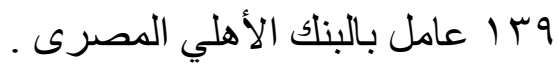

\section{عاشرا الاراسة الميدانية: ع / ا مرحلة إدخال ومعالجة البيانات}

قام الباحث بمراجعة إستمارة الإستبيان للتأكد من إكتمالها وصلاحيتها لإدخال

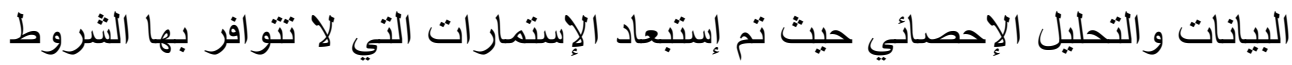

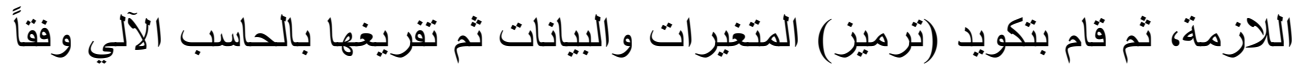

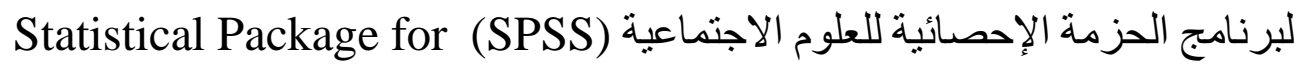
Social Sciences الحادي عشر: النتائج: النتائج الخاصة بأبعاد جودة الحئئ الحياة الوظيفية:

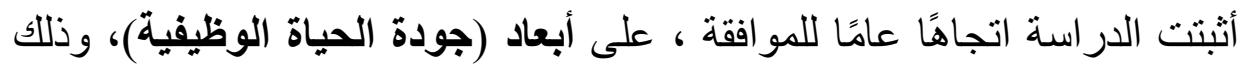

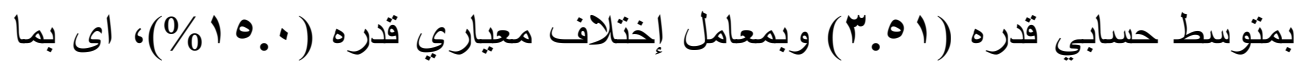

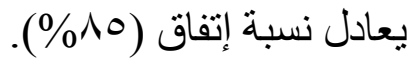
- وقد كان من أكثر الأبعاد أهمية في الإجابة على الترتيب: (جماعة العمل)،

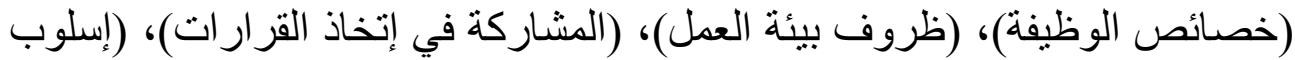

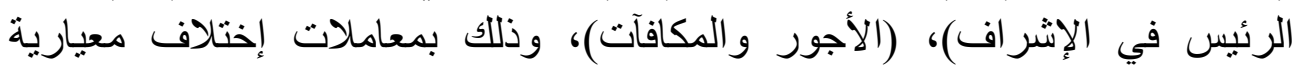

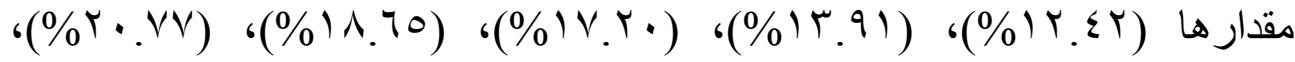

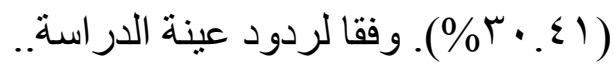

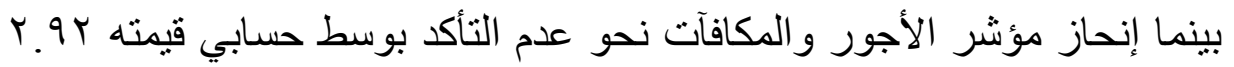

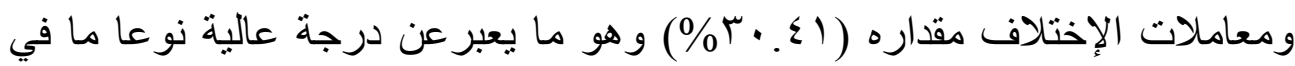




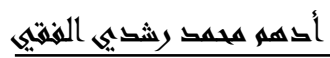

$$
\text { الإختلاف في الآراء. }
$$

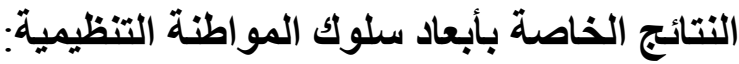

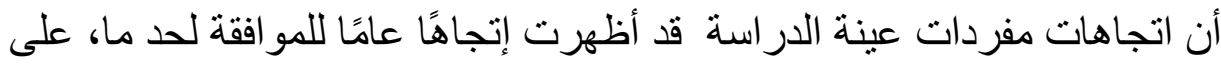

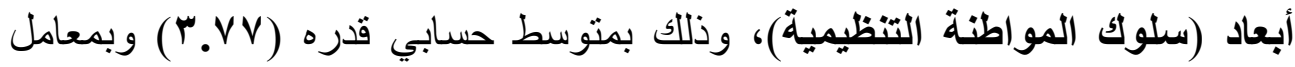

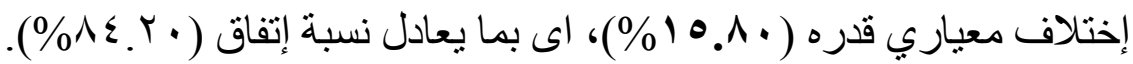

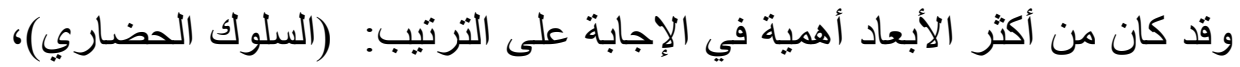
(الروح الرياضية)، (سلوك المساعدة ) )، وذلك بمعاملات إختلاف معيارية مقدارها

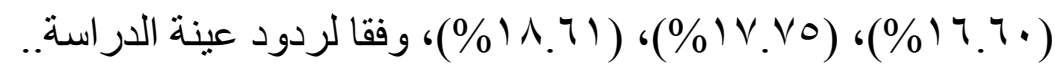

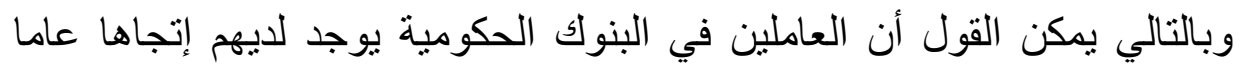

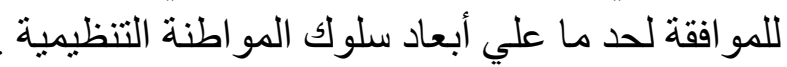

\section{الثاني عشر التوصيات:}

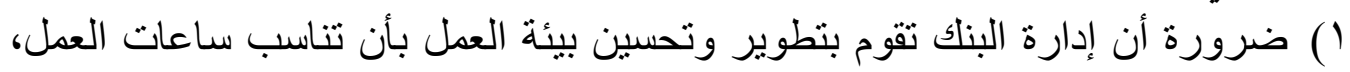

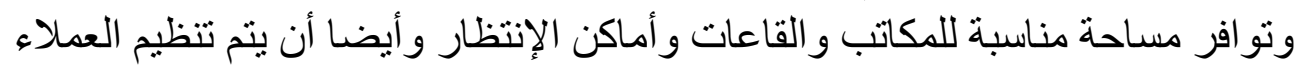

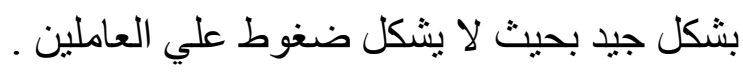

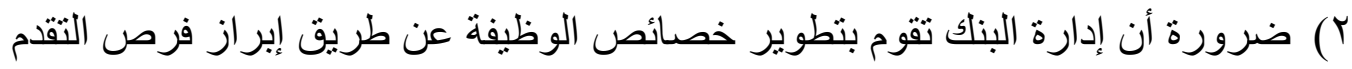

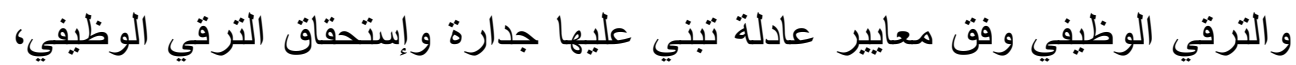

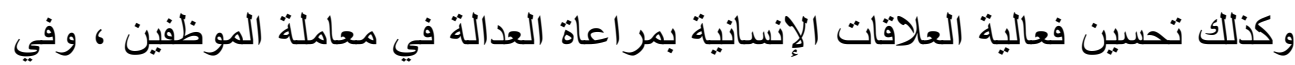

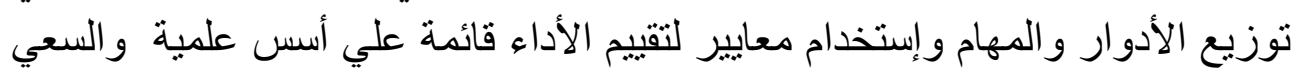

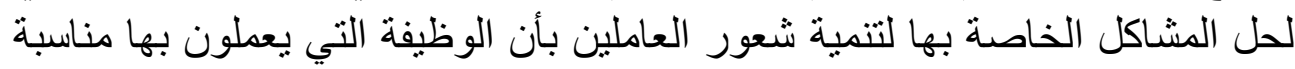

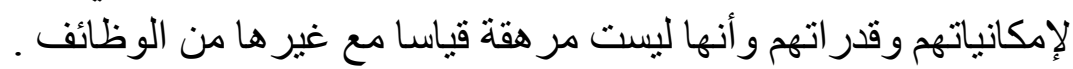

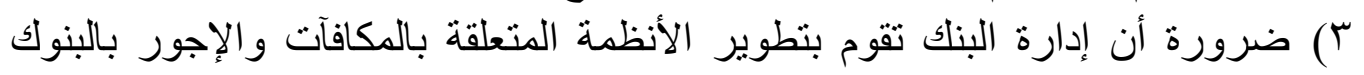

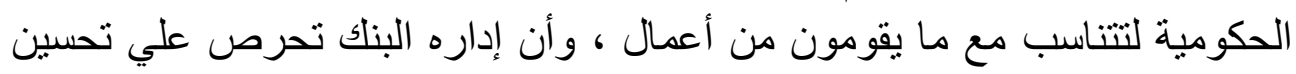

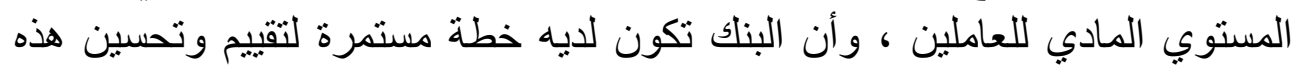

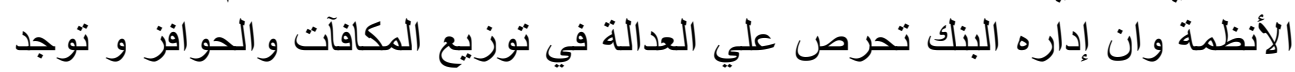

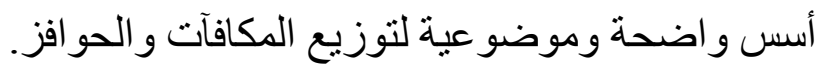
ع) يجب علي إدارة البنك أن تقوم بتنمية وتطوير جماعات العمل بتشجيع العاملين علي العمل بروح الفريق الواحد ، مما يتطلب تبني مجموعة متكاملة من البر امج التدريبية 
أثثر بوقة الحياة الموظينية هيه تنفية سلوك المواطنة التنظيميى قواسة هيح انية ....

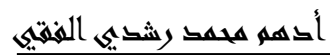

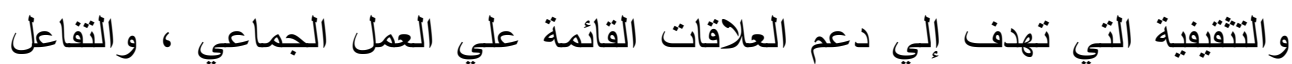
الإنساني ، و التكامل و التعاون لتحقيق أعلي إنتاجية.

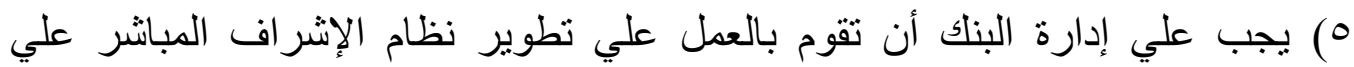

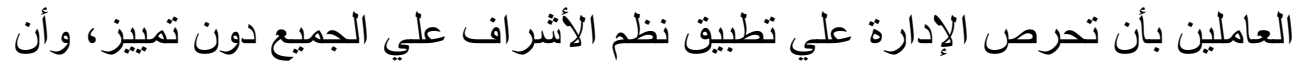
تستهدف إجراءات الإشر اف التسهيل علي العاملين والعملاء وسرعة الإدئ الإنجاز للعمل في البنك.

يجب علي إدارة البنك أن تقوم بفتح المجال امام العاملين للمشاركة في إتخاذ القرارات

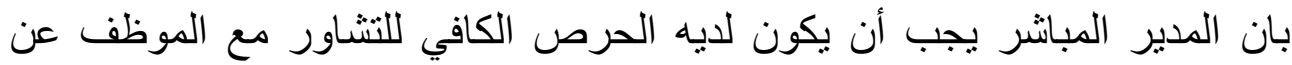

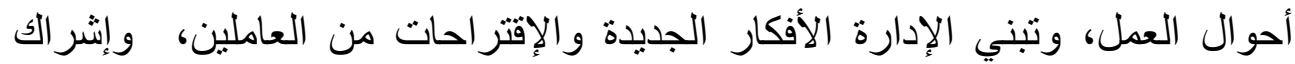

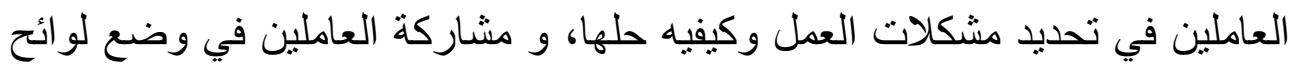
وقو اعد العمل بالبنك أو الإقتر اح بشأنها.

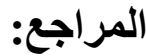

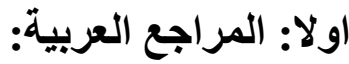

أ) للعاملين- در اسة ميدانية - رسالة ماجستير ، كلية التجارة بالإسماعيلية ، جامعة قناة السويس.

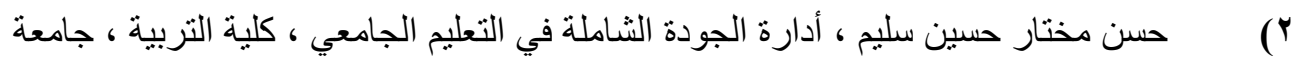

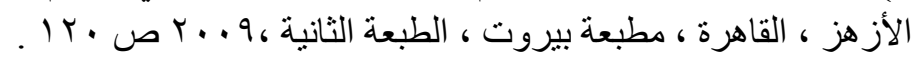

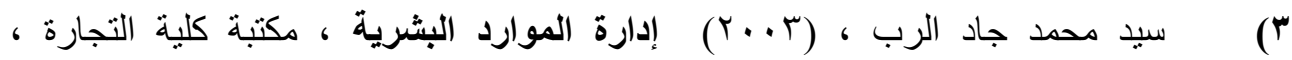

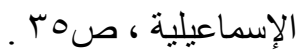
ع ) سبد محمد جاد الرب، "أدارة الموارد البشرية "، دار الكتب ، جامعة قناة السويس،

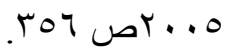

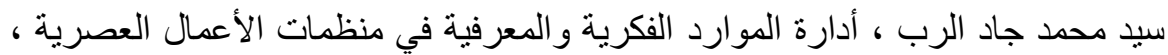

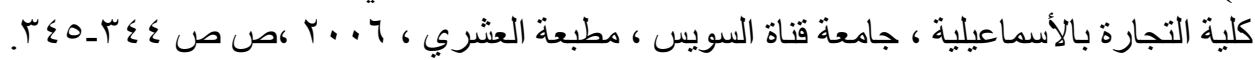

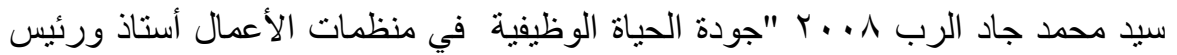

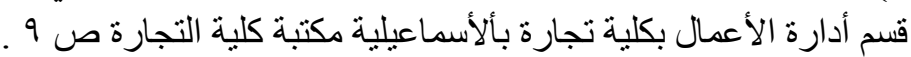

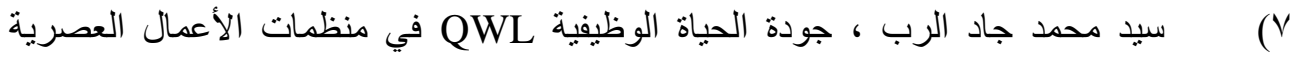

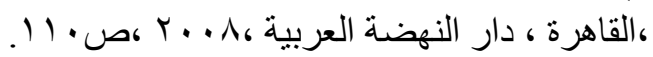




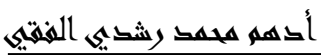

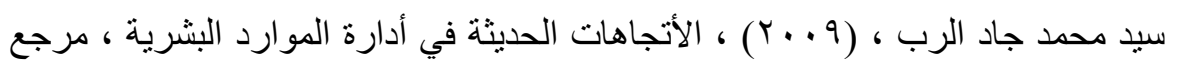

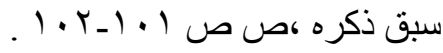
عايدة سيد خطاب ، الأدارة الأستر اتيجية للموارد البشريةـ في ظل أل أعادة الهيكلةـ الأندماج-

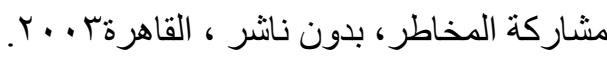

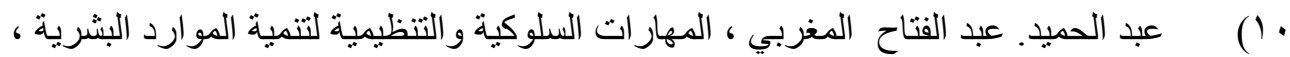

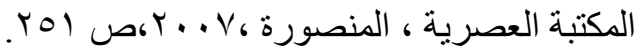

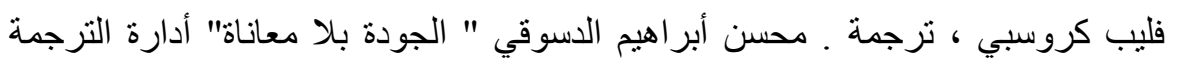

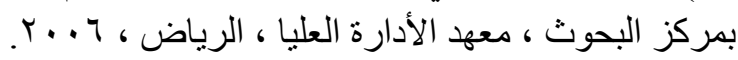

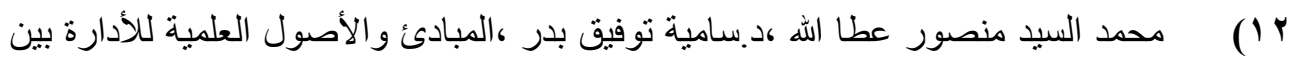

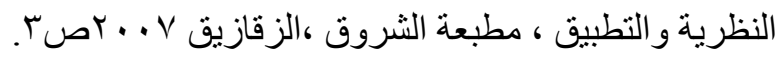

بـالأدوريات العلميةة: ( ) أحمد ماهر،(999 (19) ،" أساليب قياس جودة الحياة الوظيفية " مجلة كلية التجارة للبحوث

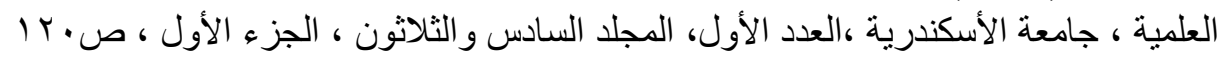

ץ) أحمد ماهر،(999 (199) ، ،" أساليب قياس جودة الحياة الوظيفية " مجلة كلية التجارة للبحوث

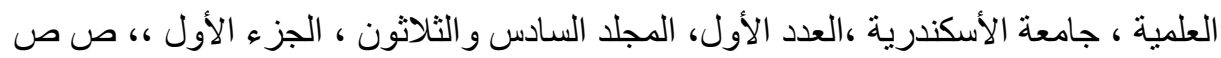
. $\left|Y \varepsilon_{-}\right| Y \mid$

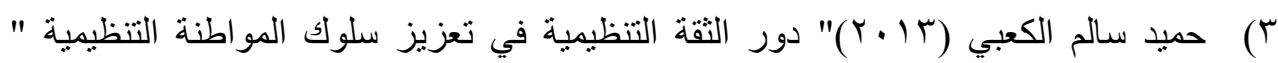
در اسة تحليلية لآراء عينة من موظفي شركة فاو الهندسية العامة وزارة الأعمار والأسكان

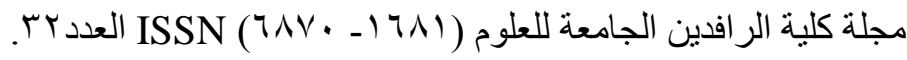
ع) رجب حسنين محمد رفاعي، المحددات ذات التأثير علي الثقة بين الرئيس والمرؤوسين و علاقتها بسلوك المواطنة التنظيمية، دراسة ميدانية، المجلة العلمية، كلية التجارة، جامعة

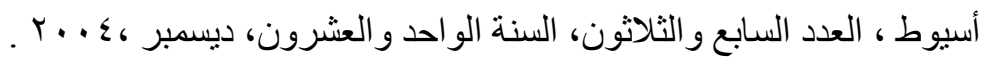

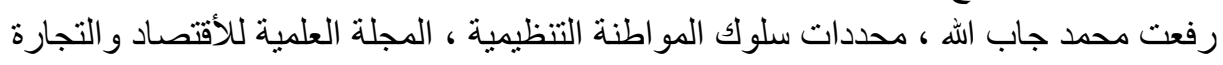

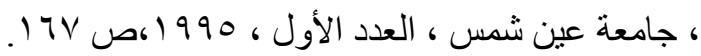

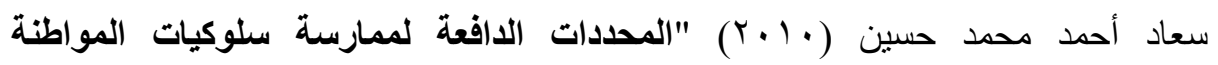
التظيمية" بالتطبيق علي المنظمات الأهلية في محافظة بورسعيد ، مجلة البحوث المالية

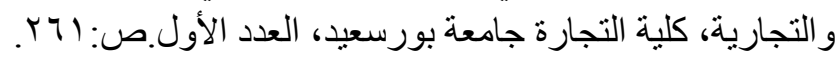

ج.الرسائل:

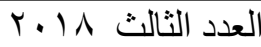
المجلد التاسع 


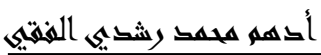

للعاملين - در اسة ميدانية _- رسالة ماجستير غير منشورة ، كلية التجارة الأسماعيلية ، جامعة

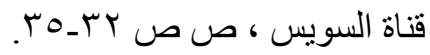

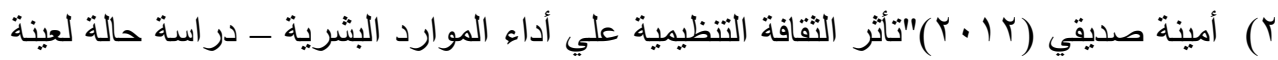
من المؤسسات الصغيرة والمتوسطة بولاية ورقلة ، رسالة ماجستير غير منشورة جامعة قاصدي مرباح الجزائر . ب) إيهاب عبداله محمد الحنفي ،" أثر جودة الحياة الوظيفية علي الأداء التظظيمي" رسالة ماجستير التير

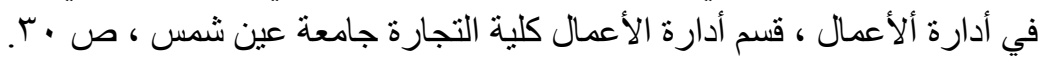
ع) سالم سعيد سالم القحطانى ، أثر الذكاء الوجداني عند المديرين علي جودة الحياة الوظيفية

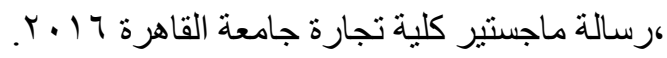

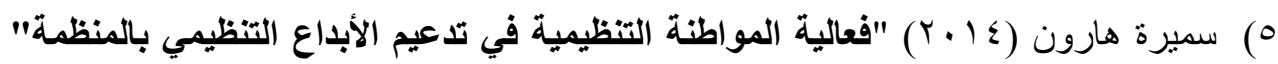
دراسة حالة للمؤسسة الوطنية للسيار ات الصناعية، رسالة ماجستير أدارة اعمال كلية العية العلوم

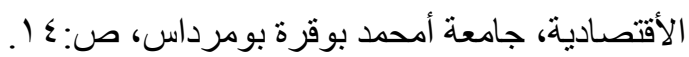

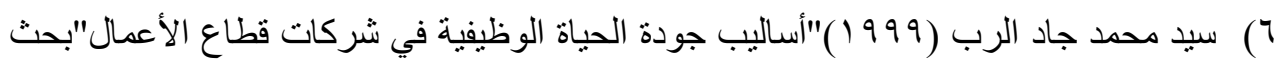

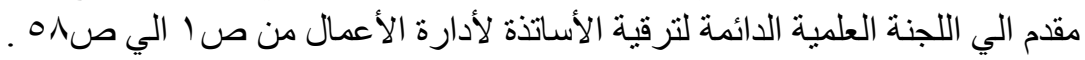

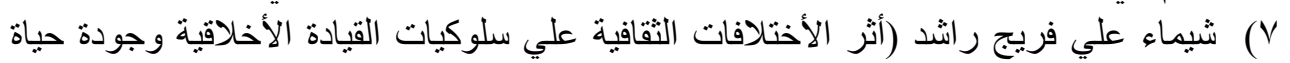
العمل في الشركات متعددة الجنسيات بجمهورية مصر العربية :رسالة دكتوراة مكتبة كلية

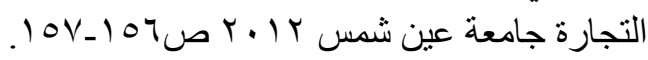
^) محمد حسين عبدالغفور برسي ، نموذج مقترح لقياس تأثير جودة الحياة الوظيفية علي أداء

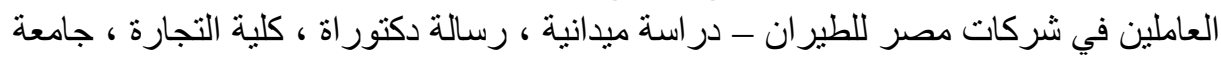

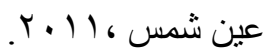

\section{ثانيا: المراجع الأجنيية:}

\section{A)Books:}

1. Barnard, C.1.(1938) The Functions of the Executive. Mass: Harvard University press.

2. Baumol,W.J.,Blinder,A.s,\&Woiff,E.N(Downsizing in America :Reality ,causes and consequences new York: Russell sage foundation, 2003.

3. Brooks, B.A. \& Gawel, S .(2001) Development and Psychometric Evaluation of the quality of Nursing Work Life Survey. Dissertation .Abstracts International :Section B .The Sciences \& Engineering, 62,1314 . 


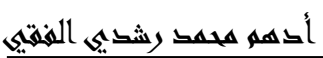

4. Cammann,c.;Fichman,m,:Jenkins d.,and klesh ,"Assessing the attitudes and perceptions of organizational members" in seashore, s.; lawler, e, mirvis , p and cammann c. (1983).

5. Chandranshu(2012).OP.Cit.p32.

6. D.Katz " The Motivation Bass of organization" Behavioral Science, Vol 9 (1964) PP131 -133 .

7. Dong-Jin Lee et al .," further Validation Of Need-Based Quality of Work Life (QWL) Measure : Evidence From marketing practitioners ", applied research quality life, Vol.02,2007 , P.273.

\section{Periodicals}

1. Armenio Rego and Miguel Pina Cunha ," Authentizotic Climates and employee happiness :Pathways to individual performance ? ", Journal of business research ,Vol.61,2008,p .739.

2. Aslan et al, (2014) " The Role of Mediator Ethical Values and Behavior Whish is Affected by Organizational Citizenship Behavior on Employee Empowerment" ,Journal of Small Business and Entrepreneurship Development, Vol .2, No. 2 ,June,P:158.

3. Blackburn, J . , \& Bruce, W.(1989). Rethinking Concepts of job satisfaction :The case of Nebraska Municipal Clerks , Review of public Personnel Administration, 10,11-29.

4. Carpenter, N. C., Berry, C. M., \& Houston, L. 2014. A meta-analytic comparison of self-reported and other-reported organizational citizenship behavior. Journal of Organizational Behavior, 35(4): 547-574.

5. Chandranshu, Sinha (2012).Factors Affecting Quality of work life. Empirical Evidence from Indian Organizations. Australian Journal of Business and Management Research. Vol.1No.11pp31-40 February2012.

6. Chandranshu, Sinha (2012) . Factors Affecting Quality of work life . Empirical Evidence From Indian Organizations Australian Journal of Business and management Research p32.

7. Chen-Wei Yu: Cheng-Min Chao: Bor-Wen Cheng (2014).Relationships 
أثر بوقة الحياة الموظهية هيه تنمية سلوك المواطنة التنظيميه قراسة هيدانية ....

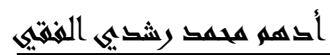

Among Work value, Quality of work life, and Turnover Intension in Nurses in Yunlin, Taiwan. International Journal of Organizational Innovation. Apr2014, Vol. 6, Issue 4, pp99108.

8. Chin, Min-Huei, (2011) " An Investigation of the Relationship of Organizational Structure, Employee's Personality and Organizational Citizenship Behavior". The Journal of American Academy of Business, Cambridge, P: 428. 